\title{
ERS/ISAM TASK FORCE REPORT
}

\section{What the pulmonary specialist should know about the new inhalation therapies}

\author{
B.L. Laube, H.M. Janssens, F.H.C. de Jongh, S.G. Devadason, R. Dhand, P. Diot, \\ M.L. Everard, I. Horvath, P. Navalesi, T. Voshaar and H. Chrystyn
}

ABSTRACT: A collaboration of multidisciplinary experts on the delivery of pharmaceutical aerosols was facilitated by the European Respiratory Society (ERS) and the International Society for Aerosols in Medicine (ISAM), in order to draw up a consensus statement with clear, up-to-date recommendations that enable the pulmonary physician to choose the type of aerosol delivery device that is most suitable for their patient. The focus of the consensus statement is the patientuse aspect of the aerosol delivery devices that are currently available.

The subject was divided into different topics, which were in turn assigned to at least two experts. The authors searched the literature according to their own strategies, with no central literature review being performed. To achieve consensus, draft reports and recommendations were reviewed and voted on by the entire panel.

Specific recommendations for use of the devices can be found throughout the statement. Healthcare providers should ensure that their patients can and will use these devices correctly. This requires that the clinician: is aware of the devices that are currently available to deliver the prescribed drugs; knows the various techniques that are appropriate for each device; is able to evaluate the patient's inhalation technique to be sure they are using the devices properly; and ensures that the inhalation method is appropriate for each patient.

KEYWORDS: Inhalation technique, inhalation therapy, inhalation treatment, pulmonary delivery

\section{CONTENTS}

Introduction ....................... 1309

Methods 1309

Pulmonary aerosol delivery: overview

Limitations of aerosol therapy

Particle- and patient-related factors that influence aerosol deposition 1310

Lung disease and deposition

Drug receptors 1311

Nasal versus oral inhalation 1311

Patient behaviour and deposition 1311

Choice of delivery device 1312

Regulation of delivery devices 1312

Recommendations 1312

Aerosol device options 1312

Pressurised metered-dose inhalers 1312

Breath-actuated pressurised metered-dose inhalers 1318

Spacers and valved holding chambers

1320

Dry powder inhalers

1321

Nebulisers

1323

Soft mist inhalers

1324

Choice of drug-device combinations to use at home
AFFILIATIONS

For a list of the authors' affiliations see the Acknowledgements section.

CORRESPONDENCE

B.L. Laube

Johns Hopkins University School of Medicine

200 North Wolfe Street

Suite 3015

Baltimore

MD 21287

USA

E-mail: blaube@jhmi.edu

Received:

Oct 252010

Accepted after revision:

Jan 052011

First published online:

Feb 102011 
Patients with pulmonary arterial hypertension . . . . . . 1324

HIV-infected (AIDS) or immunocompromised patients . 1324

Patients with cystic fibrosis . . . . . . . . . . . . . . . . 1324

Choice of drug-device combinations to use in the emergency room and in hospital . . . . . . . . . . 1325

Pressurised metered-dose inhalers with spacers versus nebulisers to administer short-acting bronchodilators in the emergency room . . . . . . . . . . . . . . . . . . . 1325

Nebulisers and patients with severe asthma and chronic obstructive pulmonary disease in the emergency room. . 1325

Nebulisers and non-cystic fibrosis diseases in hospital. . 1325

A joint Task Force of multidisciplinary experts on the delivery of pharmaceutical aerosols was approved by the European Respiratory Society (ERS) and the International Society for Aerosols in Medicine (ISAM), in order to draw up clear, up-todate recommendations that enable the pulmonary physician to choose the type of aerosol delivery device that is most suitable for their patients at home and in hospital.

Many drugs are currently delivered directly to the lungs as an aerosol. These include short-acting $\beta_{2}$-adrenergic agonists and long-acting $\beta_{2}$-adrenergic agonists (LABA), anticholinergics, inhaled corticosteroids (ICSs), nonsteroidal anti-inflammatories, antibiotics and mucolytics. Other drugs are under development for aerosol delivery. These include insulin to treat diabetes, gene therapy vectors to treat cystic fibrosis (CF), vaccines for measles and papilloma virus, chemotherapy agents for lung cancer, new formulations for antibiotics, anti-proteases to treat $\mathrm{CF}$ and $\alpha_{1}$-antitrypsin deficiency, morphine to relieve pain, and ergotamine to relieve headaches.

Devices that are available to deliver these drugs include pressurised metered-dose inhalers (pMDIs), used either alone or attached to spacers or valved holding chambers (VHCs), breathactuated (BA)-pMDIs, dry powder inhalers (DPIs), nebulisers and soft mist inhalers.

Treatment guidelines for the management of asthma [1] and chronic obstructive pulmonary disease (COPD) [2] are well established. Both recommend inhaled therapy as the primary route to administer medication. A comprehensive comparison of the dose equivalence of inhaled steroids has been presented [3]. Treatment guidelines for $\mathrm{CF}$ also include inhalation of aerosolised medications $[4,5]$.

Meta-analysis reports indicate that when patients use the inhalation technique recommended by the manufacturer, all inhalers are effective and can achieve the same therapeutic effect, although different doses may be required [6, 7]. However, many patients do not use the correct technique when using their inhalers [8], either because they have never been taught or because they have modified the technique following instruction. As is the case with most therapeutic areas, poor adherence with the optimal treatment regimen is common [9]. For this reason, treatment guidelines state that a patient's inhaler technique and their level of adherence should be determined before a change is made to a patient's prescription. They also indicate that inhaler technique should

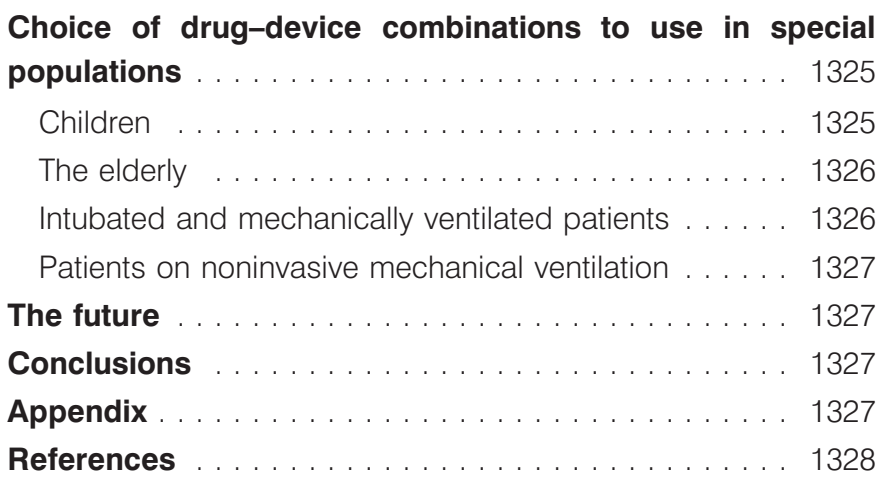

always be taught and assessed by competent healthcare professionals.

In this consensus statement, we focus on the patient-use aspect of the aerosol delivery devices that are currently available, so that prescribers understand the inhalation methods needed for these devices and can make an informed choice as to the type of device that is most suitable for their patient's use at home and in hospital. Devices under development were not included because they were not available to the physician at the time of review.

\section{METHODS}

The Task Force was composed of 11 invited participants who were identified on the basis of their expertise in the area of pulmonary aerosol delivery. The subject was divided into different topics, which were in turn assigned to at least two experts. Topic-writers searched the literature according to their own strategies and determined their own databases. No attempt was made to grade evidence or recommendations. The literature search ended in December 2009.

Draft reports written by the experts on each topic were distributed to the entire expert panel and comments were solicited in advance of meetings that were held at the 2009 ISAM Congress and the 2009 ERS Congress, as well as a small group meeting at the 2009 ERS School Course on Medical Aerosols. During these meetings, the recommendations and evidence supporting the recommendations were reviewed and discussed by the entire panel. Approval of the recommendations required consensus, which was defined as a majority approval. Differences of opinion were accommodated by revising the recommendations until consensus was reached. Despite differences between guidelines and the availability of drugs and devices, the Task Force tried its utmost to develop a consensus statement that is valid all over the world.

\section{PULMONARY AEROSOL DELIVERY: OVERVIEW}

Unlike oral or intravenous therapies, aerosolised therapy delivers drugs directly to the internal lumen of the airways and onto the therapeutic sites. For this reason, the systemic dose of most aerosolised drugs is reduced compared to oral and i.v. treatments. Direct delivery to the lungs also permits a more rapid bronchodilation in response to $\beta_{2}$-adrenergic agonists and anticholinergics, and with some LABAs the duration of the effect is enhanced compared to oral treatments. 


\section{Limitations of aerosol therapy}

Not all inhalation devices are appropriate for all patients. This is because of differences in the way the devices perform and the need to master specific inhalation techniques, which require varying levels of cognitive ability depending on the device. Reviews of randomised controlled trials comparing different inhalers have concluded that they are all equivalent $[6,7]$. However, patients in randomised controlled trials receive more inhaler-technique training and counselling on the importance of adherence than patients who are seen as part of routine clinical practice. For this reason, the Global Initiative for Asthma (GINA) and the British Thoracic Society (BTS) guidelines recommend that inhaler technique and the degree of adherence with dose regimens should be assessed before changing a patient's inhalation therapy [1-3].

Based on a real-life setting, it has been reported that $76 \%$ of patients using a pMDI and $49-54 \%$ of those using a BA-pMDI make at least one error when using their inhaler [10]. In addition, between 4 and $94 \%$ of patients using a DPI do not use it correctly and $25 \%$ have never received inhaler-technique training [11]. Failure to exhale to functional residual capacity before inhaling through their DPI device and failure to use a forceful, deep inhalation were two of the most common problems with DPIs [11]. With pMDIs, the most common problems were lack of actuation-inhalation coordination and stopping inhalation due to the cold freon effect [12]. Despite these errors, 50,66 and $70-80 \%$ of general practitioners report that their patients inhale the right dose when they use a pMDI, BA-pMDI and a DPI, respectively [10].

When patients inhale a short-acting bronchodilator, they inhale another dose if they do not obtain a sufficient response from the first dose. As a result of this, they can overcome poor technique and potentially poor disease control by increasing their dose. Patients do not get this feedback from other inhaled therapies. For those drugs, it is important that patients use their device in an optimal manner and this often requires a specific and relatively complex inhalation manoeuvre that is tailored to the patient's needs and preferences [8].

\section{Particle- and patient-related factors that influence aerosol deposition}

Table 1 provides the definitions of terms commonly used to describe an aerosol. These terms are derived from in vitro measurements of particle-related characteristics and include dose and aerodynamic diameter. In terms of dose, physicians should be particularly aware that some countries label the inhaler with the nominal dose (which is the dose that is metered), while others use the emitted dose (which is the dose that comes out of the actuator and is available for inhalation at the mouth). For example, beclomethasone pMDI (hydrofluoroalkane (HFA) formulation, $\mathrm{QVAR}_{\mathbb{B}}$ (see Appendix for all product/drug manufacturer details)) is labelled as $100 \mu \mathrm{g}$ (the nominal dose) in Europe and as $80 \mu \mathrm{g}$ (the emitted dose) in the USA. Although these two references to dose are not the same, the dose that the patient receives is the same.

Drug delivery via the respiratory tract is more complex than oral therapy. Successful therapy requires a delivery system that generates drug particles of an appropriate size, such that they penetrate beyond the oropharynx and larynx and deposit in the lungs [13]. Aerodynamic diameter is generally thought to be the most important particle-related factor that affects aerosol deposition. Figure 1 shows the relationship between aerodynamic diameter and lung deposition [14]. Upon entering the oral cavity, particles will deposit by impaction, sedimentation and Brownian motion depending on their size. Particles $>5 \mu \mathrm{m}$ are most likely to deposit by impaction in the oropharynx and be swallowed [13]. This is partially the result of the inertia associated with the particle's mass, which reduces its ability to follow the airstream when it changes direction toward the lower airways. It is important to minimise corticosteroid deposition in the oropharynx because it can give rise to local side-effects, such as hoarseness and oral candidiasis with ICS [15].

Figure 1 also shows that particles that are $<5 \mu \mathrm{m}$ have the greatest potential for deposition in the lungs. The proportion of particles within an aerosol that are $<5 \mu \mathrm{m}$ is often referred to as the fine-particle fraction (FPF), or the fine-particle dose (FPD) if expressed in absolute mass of drug in particles $<5 \mu \mathrm{m}$ (table 1). Aerosols with high FPFs have a high probability of penetrating beyond the upper airways and depositing in the lungs. Thus, it is not surprising that current devices generate aerosols with a significant proportion of their particles in the 1-5 $\mu \mathrm{m}$ range. The optimal particle size range for aerosols delivered to children is not known. It is likely that it is smaller than the optimal size range for adults, due to narrower airway diameters and higher intraluminal flows.

Figure 1 shows that particles of $4-5 \mu \mathrm{m}$ deposit primarily in the bronchial/conducting airways, whereas smaller particles remain in the airstream and are carried into the peripheral airways and the alveolar region. In the periphery of the lung, airflow rate is reduced and particles deposit predominantly by sedimentation, with gravity causing them to "rain out" and deposit. Most particles of $0.1-1 \mu \mathrm{m}$ diffuse by Brownian motion and deposit when they collide with the airway wall. The longer the residence time in the smaller, peripheral airways, the greater the deposition from sedimentation and Brownian motion processes [16]. It is recommended that patients hold their breath after inhalation of an aerosolised medication because the breath-hold increases the residence time and this enhances deposition in the peripheral airways. Inhaled particles that do not deposit are exhaled [13].

Important patient-related factors include the morphology of the oropharynx and larynx and the patient's inspiratory volume and flow rate. The patient's inspiratory flow rate generally determines the velocity of the airborne particle and this, in turn, also affects the probability of its impaction in the oropharynx and larynx [17]. To minimise deposition in the upper airways and enhance delivery of the drug to the lungs when using a pMDI with or without a spacer, or a BA-pMDI, patients should inhale slowly. "Slowly" translates into inhaling fully over 2-3 s in a child and 4-5 s in an adult after a deep exhalation. This ensures that flows are $\sim 30 \mathrm{~L} \cdot \mathrm{min}^{-1}$, which is the ideal flow when using a pMDI [18]. With DPIs, the patient has to inhale as deeply and as hard as they can to overcome the internal resistance to flow and generate the aerosol for inhalation. DPIs also require turbulent energy to de-aggregate their formulations and produce a FPD during the inhalation manoeuvre. The greater the energy imparted by the patient's 


\section{TABLE 1 Definitions of commonly used terms that describe an aerosol}

\begin{tabular}{|c|c|c|}
\hline Term & Abbreviation & Definition \\
\hline Labelled dose or nominal dose ${ }^{\#}$ & & The mass of drug that is available within the aerosol generator per actuation. This is the dose that is metered. \\
\hline Fine-particle dose & FPD & The mass of particles $<5 \mu \mathrm{m}$ in size within the total emitted dose. \\
\hline Fine-particle fraction & FPF & The fine particle dose divided by the total emitted dose. \\
\hline Aerodynamic equivalent diameter & dae & $\begin{array}{l}\text { The diameter of a fictitious sphere of unit density }\left(1 \mathrm{~g} \cdot \mathrm{cm}^{-3}\right) \text { that has the same gravitational } \\
\text { (settling) velocity in the same gas as the actual particle. }\end{array}$ \\
\hline Geometric standard deviation & og or GSD & $\begin{array}{l}\text { The GSD measures the dispersion of particle diameter and is defined as the ratio of the median } \\
\text { diameter to the diameter at } \pm 1 \text { SD }(\sigma) \text { from the median diameter. In a cumulative distribution plot } \\
\text { of the aerodynamic diameter and mass of particles, the GSD is calculated as the ratio of the } \\
\text { median diameter to the diameter at } 15.9 \% \text { of the probability scale, or the ratio of the diameter at } \\
84.1 \% \text { on the probability scale to the median diameter. Aerosols with a GSD } \geqslant 1.22 \text { are considered } \\
\text { polydisperse. Most therapeutic aerosols are polydisperse and have GSDs in the range of } 2-3 \text {. }\end{array}$ \\
\hline
\end{tabular}

inspiratory flow rate, the more effective the particle deaggregation.

\section{Lung disease and deposition}

The degree of lung disease at the time of inhalation significantly influences the pattern of drug deposition within the lungs. Several studies have shown that central airway deposition is enhanced as mucus plugging, turbulent airflow and airway obstruction increase [19-23]. This means that in the face of severe lung disease, little or no drug may deposit in the lung periphery. This may not be clinically important for bronchodilators, but could be important for corticosteroids.

\section{Drug receptors}

Receptors for inhaled bronchodilators are distributed throughout the lungs $[24,25]$, but they have their greatest effect on

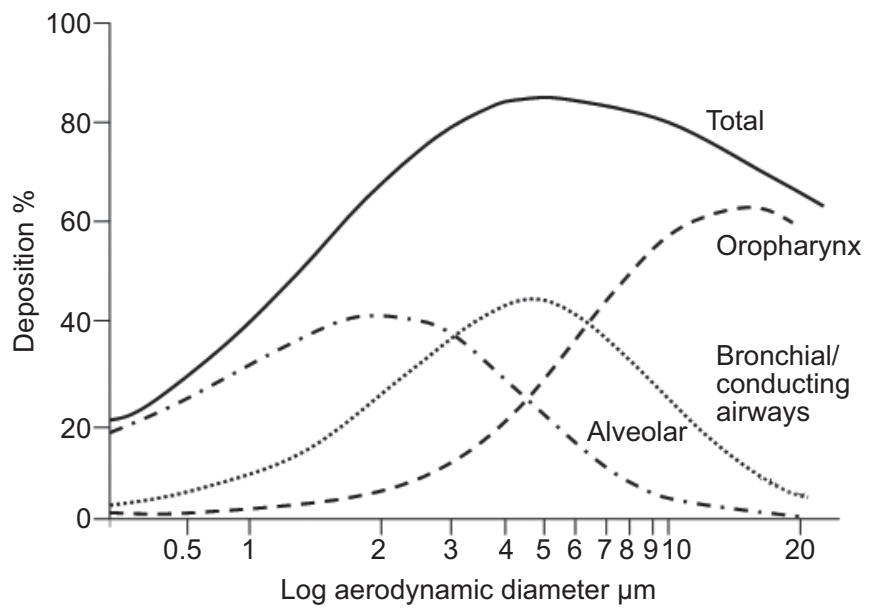

FIGURE 1. The International Commission on Radiological Protection model showing the relationship between aerodynamic diameter and lung deposition. Data from [14]. receptors in the smooth muscle located in the conducting airways. By targeting these receptors, bronchodilators open up (dilate) the larger airways.

Corticosteroid receptors are also present throughout the airways [26] and inflammation has been shown to exist in all regions of the lungs in asthma [26] and COPD [27]. For these reasons, uniform distribution of an ICS throughout the airways, following inhalation, may be preferable. Further studies are needed to confirm this before recommendations can be made. Furthermore, there is doubt about the effectiveness, or role, of ICS in COPD [28], as reflected in the Global Initiative for Chronic Obstructive Lung Disease (GOLD) guidelines [2].

\section{Nasal versus oral inhalation}

The nose is a more effective filter than the mouth. Thus, inhalation through the mouth is the preferred route for aerosol delivery to the lungs. This is a potential issue when treating infants and toddlers. For example, when children are treated with nebulisers, or pMDIs with spacers or holding chambers, they frequently breathe through their noses using a facemask. While absolute efficiency in terms of lung dose is low during nose breathing, compared to mouth breathing [29], the total inhaled dose per $\mathrm{kg}$ of body weight is relatively higher in nose-breathing children compared with older patients using mouthpieces. Therefore, the dose to the lungs per $\mathrm{kg}$ body weight in nose-breathing infants is probably similar to that achieved by mouth-breathing adults [29].

\section{Patient behaviour and deposition}

For inhaled therapy to be effective, the patient must use a device effectively and adhere to a regular treatment regimen [8]. Adherence to treatment regimens is known to be frequently poor in all therapeutic areas and is probably not significantly worse with inhaled as compared with oral therapy. However, even if a patient is fully adherent with a treatment 
regimen, inhaled therapy may be ineffective if poor inhalation technique limits the amount of drug available for lung deposition. Studies have shown that a very high proportion of patients do not have the competence to use their device effectively, either because they have never been shown or because they have forgotten what they were taught $[8,30]$. This is a particular problem in the elderly, but it does affect all age groups. Furthermore, many patients soon forget the correct technique that they have been trained to use [31]. In addition, many of those who are able to demonstrate a good technique in the clinic will contrive to use the device ineffectively in routine use. The most common example of contrivance is spacer disuse (e.g. patient's failure to use a spacer at home).

Data regarding the impact of education on regimen adherence is at best mixed, and it is very difficult to influence this aspect of patient behaviour. Having a good rapport with the patient has been shown to improve regimen adherence after a consultation, but this may be as transient as 1 week [31]. Patients may be more adherent with an inhaler that combines two drugs (i.e. LABA and ICS) in the same dose, compared with using two separate inhalers [32]. Although this may simplify the regimen, the effect is far from universal. While education per se probably does not have a significant impact on regimen adherence, patient feedback in terms of regimen adherence and automated reminders appear to influence this aspect of behaviour and are likely to become more frequently employed in clinical practice in the future [33].

Healthcare providers have a particular duty to ensure that patients are able to use their inhalers effectively [8]. Physicians must ensure that a suitable device is prescribed, that the patient is competent in the use of it and that the patient understands that little or no drug may reach the lungs if the device is not used according to the specified instructions. Competence and contrivance are amenable to educational intervention, though it is important to review these issues with the patient on a regular basis. Once a patient is familiar and stabilised on one type of inhaler, they should not be switched to new devices without their involvement and without followup education on how to use the device properly.

\section{Choice of delivery device}

The choice of device for a particular drug is determined by the devices that are available for that drug and whether the patient can and will use it effectively. Table 2 provides a summary of the devices that are currently available for delivery of the most commonly prescribed brand-name drugs, broken down according to pMDIs, BA-pMDIs, nebulisers, soft mist inhalers and DPIs. A pMDI requires good actuation-inhalation coordination for optimal lung deposition, whereas a DPI requires sufficient inspiratory flow. Table 3 provides information for choosing the right aerosol delivery device for patients with good versus poor actuation-inhalation coordination and sufficient inspiratory flow [34]. Patients with poor actuationinhalation coordination include children and elderly patients. Where possible, patients should use one type of device for all of their inhaled therapies [1, 3]. However, this is not always possible. In the USA, there is no salbutamol DPI; patients may therefore have to use both a pMDI for their $\beta_{2}$-adrenergic agonist and a DPI for their other prescribed medications.
Although previous publications have provided general inhalation technique recommendations for inhalers [7, 35], table 4 provides more detailed instructions on how to use pMDIs, BApMDIs, pMDIs with spacers, DPIs, nebulisers and soft mist inhalers. The major advantages and disadvantages of pMDIs with and without spacers, BA-pMDIs, nebulisers and DPIs are summarised in table 5 [9].

\section{Regulation of delivery devices}

In Europe, aerosol devices are regulated by the European Medicines Agency (EMA; www.ema.europa.eu). In the USA, the regulatory agency is the Food and Drug Administration (www.fda.gov).

\section{Recommendations}

Prescribers should:

1) Know the types of devices that are available to deliver specific drugs and classes of drugs (table 2).

2) Appreciate the advantages and disadvantages of each device (table 5).

3) Choose devices that the patient can and will use effectively (table 3).

4) Choose devices that have been approved by the appropriate authorities (table 2).

5) Train patients about the correct inhalation manoeuvre that is appropriate for the device being prescribed (table 4).

6) Check the patient's inhaler technique regularly.

7) Review the patient's adherence to treatment at each visit.

8) Not switch to a new device without the patient's involvement and without follow-up education on how to use the device properly.

\section{AEROSOL DEVICE OPTIONS Pressurised metered-dose inhalers}

Transition to HFA products

The pMDI was introduced in the 1950s as the first portable, multi-dose delivery system for bronchodilators. It is still the most widely prescribed inhalation device. Until recently, the drugs delivered by pMDIs were formulated with chlorofluorocarbon (CFC) propellant and small amounts of excipients (such as valve lubricants). CFCs are now being replaced by HFAs due to a ban on CFCs. At present, there are only a few pMDIs that still contain CFCs. In most European countries, CFC-pMDIs have been totally replaced by non-CFC inhalers. After 2013, CFC-pMDIs will no longer be available in the USA [36]. Table 2 presents drugs that are delivered by HFA- versus CFC-pMDIs.

There are some differences between the CFC and HFA products. Two of the major differences are that the plume released from many HFA-pMDIs has a slower velocity and is warmer [37]. These changes partially overcome the cold freon effect that has caused some patients to stop inhaling their CFCpMDIs [12]. Another difference is that many HFA-pMDI formulations contain a small amount of ethanol. This affects the taste, as well as further increasing the temperature and decreasing the velocity of the aerosol. Exceptions to the alcohol 
TABLE 2 Devices currently available for delivery of commonly prescribed brand-name drugs by pressurised metered-dose inhalers (pMDI), breath actuated (BA)-pMDIs, nebulisers, soft mist inhalers and dry powder inhalers (DPI)

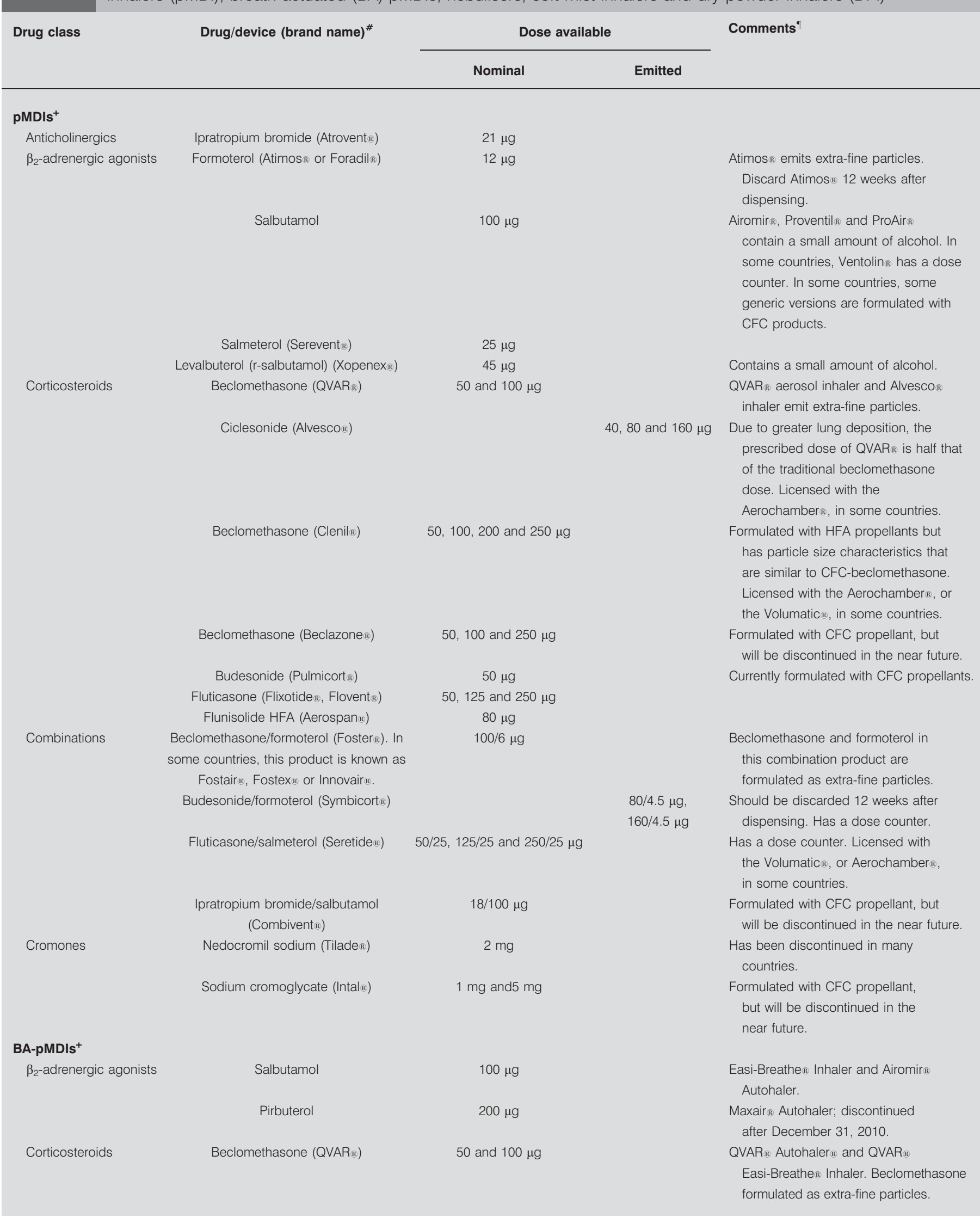




\section{TABLE 2 Continued}

\section{Drug class}

Drug/device (brand name)

Dose available

\section{Comments}

\section{Nominal}

Emitted

\section{Nebulisers}

$\beta_{2}$-adrenergic agonists

Nonsteroidal

anti-inflammatories

Antibiotics

Corticosteroids

Mucolytics

Prostacyclin

Anticholinergics

Anti-infective

\section{Soft mist inhalers}

Anticholinergics

Combinations

\section{DPIs}

Aerolizer ${ }^{\circledR}$

Diskhaler ๕
Formoterol fumarate inhalation solution (Perforomist $\_$)

Salbutamol inhalation solution

Arformoterol tartrate ( $r$-formoterol) inhalation solution

Levalbuterol (r-salbutamol) inhalation solution

Metaproterenol sulfate (Alupent $\ll$ ) Cromolyn sodium

Tobramycin inhalation solution

Colistin inhalation solution (Promixin $\mathbb{E}$ )

Aztreonam inhalation solution

$$
\text { (Cayston }{ }_{\mathbb{B}} \text { ) }
$$

Budesonide inhalation suspension

Fluticasone inhalation suspension

Recombinant human DNase

(Pulmozyme $\mathbb{R}$ )

Hypertonic saline inhalation solution

Hyper-Sal $^{\mathrm{TM}}$
MucoClear $^{\mathrm{B}}$
Hyaneb $^{\mathrm{TM}}$

lloprost (Ventavis $\mathbb{R}$ )

Ipratropium bromide (Atrovent ${ }_{\Re}$ )

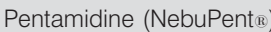

Tiotropium bromide

Fenoterol/ipratropium bromide

Budesonide

Formoterol

Beclomethasone

$20 \mu \mathrm{g} / 2 \mathrm{~mL}$

$0.083 \%$

Vials with 1,2 and $5 \mathrm{mg} \cdot \mathrm{mL}^{-1}$

$15 \mu \mathrm{g}$

$0.31 \mathrm{mg} / 3 \mathrm{~mL}, 0.63 \mathrm{mg} / 3 \mathrm{~mL}$ and $1.25 \mathrm{mg} / 3 \mathrm{~mL}$

$0.5,0.6$ and $5 \%$

$20 \mathrm{mg}$

$300 \mathrm{mg} / 5 \mathrm{~mL}\left(\left.\mathrm{TOB}\right|_{\ltimes}\right)$

$300 \mathrm{mg} / 4 \mathrm{~mL}$ (Bramitob $\mathrm{R}$ )

Vial with powder: 1 million units (80 $\mathrm{mg}$ ) with water and saline for solution $(3 \mathrm{~mL})$

$75 \mathrm{mg} / 2 \mathrm{~mL}$

0.25, 0.5 and $1 \mathrm{mg}$ (Pulmicort Respules $\mathbb{B}$ ) 0.25 and $0.5 \mathrm{mg}$ (generic) $0.50 \mathrm{mg} / 2 \mathrm{~mL} ; 2 \mathrm{mg} / 2 \mathrm{~mL}$ (Flixotide ${ }^{\circledR}$ )

$2.5 \mathrm{mg} / 2.5 \mathrm{~mL}$
$3.5 \% / 4 \mathrm{~mL}$ and $7 \% / 4 \mathrm{~mL}$

$6 \% / 4 \mathrm{~mL}$

$7 \% / 5 \mathrm{~mL}$

$2.5 \mu \mathrm{g}$ per ampule and $5 \mu \mathrm{g}$ per ampule

500/vial

$0.02 \%, 300 \mathrm{mg}$
Vials do not require dilution.

Add saline until 4-mL total for jet nebuliser.

Store in foil pouch. Once pouch is opened, use vials within 2 weeks.

Can be mixed with salbutamol inhalation solution in nebuliser

Licensed for use with PARI LC $C_{\mathbb{R}}$

Plus nebuliser and Devilbiss ${ }_{R}$

Pulmo-Aide ${ }_{\circledR}$ compressor.

Licensed for use with PARI LC ${ }_{\mathbb{R}}$ Plus and PARI TURBO BOy ${ }_{\mathbb{B}}$ compressor.

Licensed for use with jet nebuliser (PARI LC ${ }_{\mathbb{B}}$ Plus or similar nebuliser) with appropriate compressor. Licensed for use with the I-neb a adaptive aerosol delivery system, in some countries.

Licensed for use with the eFlow in some countries

Licensed for use with jet-nebulisers.

Not for use with ultrasonic nebuliser.

Licensed for use with many nebulisers (see text for details). Should not be used with ultrasonic nebulisers. Fluid should not be diluted or mixed with other drugs.

Studied with jet nebulisers and breath-enhanced nebulisers with appropriate compressors.

Also contains sodium hyaluronate $0.1 \%$. Licensed for use with I-neb adaptive aerosol delivery system.

Can be combined with salbutamol,

or metaproterenol, solutions.

Licensed with Respigard II nebuliser.

Respimat $\mathbb{R}$

Respimat $\mathbb{R}$

Capsule, low resistance.

Capsule (8 or 4), low resistance. 


\section{TABLE 2 Continued}

\begin{tabular}{|c|c|c|c|c|}
\hline \multirow[t]{2}{*}{ Drug class } & \multirow[t]{2}{*}{ Drug/device (brand name) } & \multicolumn{2}{|c|}{ Dose available } & \multirow[t]{2}{*}{ Comments } \\
\hline & & Nominal & Emitted & \\
\hline & Fluticasone & 100,250 and $500 \mu \mathrm{g}$ & & \\
\hline & Salmeterol & $50 \mu \mathrm{g}$ & & \\
\hline & Zanamivir (antiviral) & $5 \mathrm{mg}$ & & \\
\hline \multirow{3}{*}{$\begin{array}{l}\text { Diskus (Accuhaler® in } \\
\text { the UK) }\end{array}$} & Salbutamol & $200 \mu \mathrm{g}$ & & \\
\hline & Salmeterol & $50 \mu \mathrm{g}$ & & \\
\hline & Fluticasone/salmeterol & $100 / 50,250 / 50$ and $500 / 50 \mu \mathrm{g}$ & & \\
\hline Clickhaler $_{\mathbb{B}}$ & Beclomethasone & 50,100 and $250 \mu \mathrm{g}$ & & $\begin{array}{l}\text { Multi-dose reservoir, medium/high } \\
\text { resistance. }\end{array}$ \\
\hline \multirow{2}{*}{ Cyclohaler ${ }_{\mathbb{B}}$} & Budesonide & 200 and $400 \mu \mathrm{g}$ & & \\
\hline & Salbutamol & $200 \mu \mathrm{g}$ & & \\
\hline \multirow[t]{4}{*}{ Easyhaler $\mathbb{B}$} & Beclomethasone & 100,200 and $400 \mu \mathrm{g}$ & & Multi-dose reservoir, high resistance. \\
\hline & Budesonide & 100,200 and $400 \mu \mathrm{g}$ & & \\
\hline & Formoterol & $12 \mu \mathrm{g}$ & & \\
\hline & Salbutamol & 100 and $200 \mu \mathrm{g}$ & & \\
\hline Handihaler ${ }_{\mathbb{B}}$ & Tiotropium & $18 \mu \mathrm{g}$ & & Capsule, high resistance. \\
\hline Maghaler® & Budesonide & $200 \mu \mathrm{g}$ & & Multi-dose reservoir. \\
\hline \multirow[t]{3}{*}{ Novolizer ${ }_{B}$} & Budesonide & $200 \mu \mathrm{g}$ & & $\begin{array}{l}\text { Multi-dose reservoir, medium } \\
\text { resistance. }\end{array}$ \\
\hline & Formoterol & $12 \mu \mathrm{g}$ & & \\
\hline & Salbutamol & $100 \mu \mathrm{g}$ & & \\
\hline \multirow{3}{*}{ Turbuhaler ${ }_{\mathbb{B}}$} & Formoterol & 6 and $12 \mu \mathrm{g}$ & & \\
\hline & Terbutaline & $500 \mu \mathrm{g}$ & & \\
\hline & Budesonide/formoterol & $100 / 6,200 / 6$ and $400 / 12 \mu \mathrm{g}$ & & \\
\hline Twisthaler ${ }_{\bar{B}}$ & Mometasone & $\begin{array}{c}200 \text { and } 400 \mu \mathrm{g} ; 220 \text { and } \\
110 \mu \mathrm{g} \text { (in US.) }\end{array}$ & & Multi-dose reservoir, high resistance. \\
\hline
\end{tabular}

\#: not all drugs/devices are available in all countries. ": for all drugs, patients should be monitored for side-effects. ${ }^{+}$: pMDIs and BA-MDIs formulated with hydrofluoroalkane (HFA) propellant unless otherwise stated in the comments column. The dose of reformulated product is the same as the chlorofluorocarbon (CFC) version unless specified. See Appendix for all product/drug manufacturer details.

content and decreased plume velocity are salbutamol (Ventolin $\left.{ }^{\circledR}\right)$, fluticasone and salmeterol pMDIs, and pMDIs with the combination of fluticasone and salmeterol (Seretide ${ }^{\circledR}$ ) and bude-

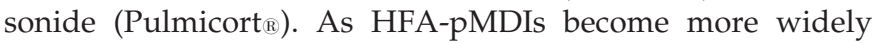
used, patient feedback regarding the perception of differences between them and CFC-pMDIs is diminishing. Nevertheless, when physicians prescribe HFA formulations in place of CFC versions for the first time, they should inform their patients about the differences in taste and sensation.
Cleaning instructions have not been altered for HFA-pMDIs. Each HFA-pMDI product provides information on its use and maintenance in its patient information leaflet (PIL). Patients should be encouraged to follow those cleaning instructions. The patient should also be instructed that on first use, and after several days or weeks of disuse, the pMDI should be primed. Priming the pMDI involves discharging two to four doses into the surrounding air (away from the patient). Patients should be encouraged to follow the priming instructions described in the PIL. 


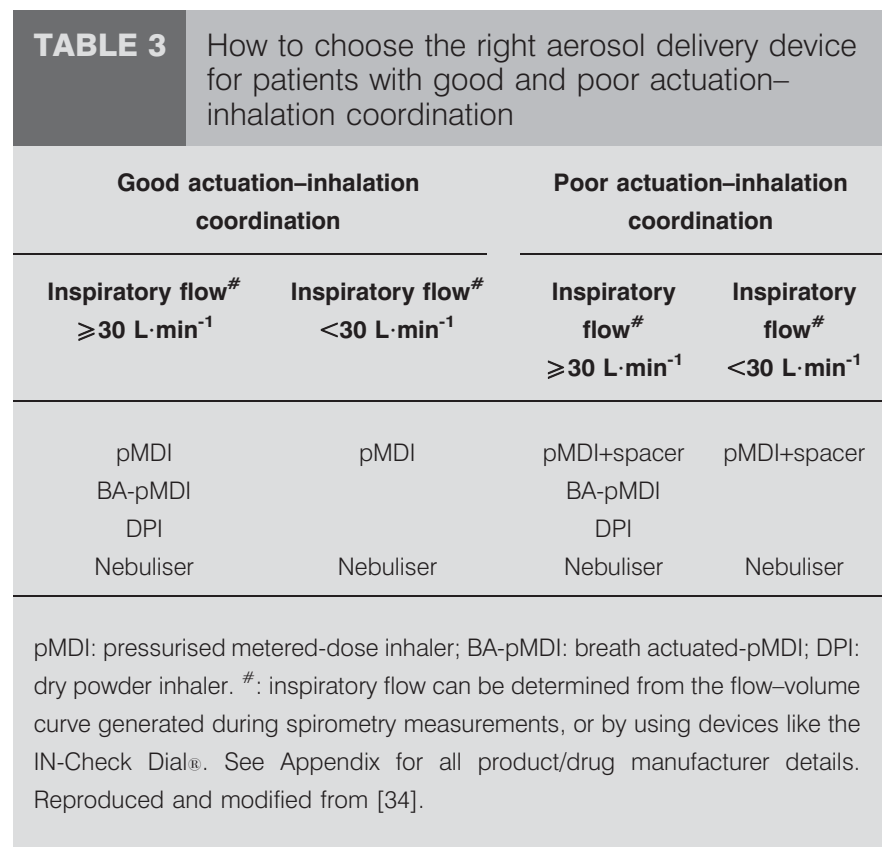

\section{Bronchodilators}

Salbutamol, formoterol and salmeterol are all available as pMDIs with HFA propellants (see table 2). In Europe, generic formulations of salbutamol are available both with CFC and HFA propellants. There is currently no generic salbutamol available in the USA.

All HFA formulations of formoterol have to be stored at $0-4{ }^{\circ} \mathrm{C}$ prior to dispensing, in order to prolong their shelf life. Since it cannot be guaranteed that patients will store these products in a cool place, the dispensing label states that they should not be used 12 weeks after the date of dispensing.

Terbutaline is no longer available as a pMDI. Ipratropium bromide is available with HFA propellant. Tiotropium bromide is available in a soft mist inhaler and in a DPI. At present, the combination of salbutamol sulfate and ipatropium bromide is available with CFC propellant.

\section{Inhaled corticosteroids}

The changeover from CFC to HFA propellant was seamless for budesonide and fluticasone, such that the new and old formulations have similar aerosol properties and no change in dose is recommended. However, the reformulation of beclomethasone has not been as straightforward and has led to formulations with different aerosol characteristics and doses, thereby generating some confusion among prescribers. The two currently available HFA-pMDIs for beclomethasone, QVAR $_{\circledast}$ HFA-pMDI and Clenil ${ }^{\circledR}$, are both solution aerosols. Solutions are comprised of drug dissolved in a carrier liquid. These two products are not dose equivalent. Thus, in countries where both products are available, regulatory authorities require prescribers to name the brand rather than simply prescribe beclomethasone HFA-pMDI.

QVAR $_{\circledR}$ aerosol particles are much smaller than particles emitted from the CFC suspension product. The mass median aerodynamic diameter (MMAD) of $\mathrm{QVAR}_{\mathbb{B}}$ is $1.1 \mu \mathrm{m}$, which makes the particles extra-fine. Extra-fine particles are sometimes also referred to as ultra-fine particles. Because of its extra-fine particles and greater FPD, inhalation of QVAR $\mathbb{R}_{\mathbb{R}}$ beclomethasone leads to more efficient lung deposition and lower oropharyngeal deposition than the CFC formulation [38, 39]. In addition, clinical trials have demonstrated that one dose of extra-fine HFA-beclomethasone is clinically equivalent to 2.6 times the dose of CFC-beclomethasone [40]. In practice guidelines (GINA and BTS), it is now recommended that $100 \mu \mathrm{g}$ of beclomethasone in a QVAR ${ }_{\circledR}$ HFA-pMDI is equivalent to $200 \mu \mathrm{g}$ in a CFC-beclomethasone pMDI. Equivalence data is based on mean data and does not necessarily apply to individuals. Healthcare providers should be aware that regulatory agencies in many countries have approved this new dosing.

Another advantage of inhaling extra-fine beclomethasone is that the timing of actuation and inhalation is not as critical [41], and due to the extra-fine particles, lung deposition is less affected by inhalation flow rate [17]. Thus, the problems patients have with coordination and inhalation are relatively less important. It also does not appear to be important that $\sim 10 \%$ of the dose is exhaled (due to the extra-fine particles), since the lung deposition is $>50 \%$ [39]. Finally, deposition of QVAR ${ }_{\circledR}$ appears evenly distributed in the different lung regions. Whether this increase in deposition uniformity improves treatment of inflammation in peripheral lung regions warrants investigation.

Clenil $_{\circledast}$ is an HFA-beclomethasone product that was developed with the intention of providing dose and particle size characteristics similar to the beclomethasone-CFC pMDI product. It is a solution that was formulated with glycerol to make the particles larger, so the particles are not extra-fine. No dose change is recommended when converting from CFC-beclomethasone to HFA Clenil $₫$.

A beclomethasone/formoterol combination has also been introduced as an HFA-pMDI solution (Foster ${ }^{\circledR}$ ). Aerosol particles for both drugs in this product are extra-fine (the MMAD of beclomethasone and formoterol are 1.3 and $1.4 \mu \mathrm{m}$, respectively) [42]. In different countries, this product is also known as Fostair $_{\circledR}$, Fostex $_{\circledR}$ or Innovair ${ }_{\circledR}$. Studies have demonstrated that two inhalations of the beclomethasone/formoterol 100/6 $\mu \mathrm{g}$ HFA-pMDI product twice daily is clinically equivalent to two inhalations of fluticasone/salmeterol $125 / 25 \mu \mathrm{g}$ twice daily (Seretide ${ }^{\circledR}$ ) [43] and to two inhalations of budesonide/formoterol 200/6 $\mu \mathrm{g}$ from a Turbuhaler® twice daily [44].

Another corticosteroid, ciclesonide (Alvesco $®$ ), is available as an HFA-pMDI product. It was also formulated as a solution and has a lung deposition profile that is similar to extra-fine beclomethasone pMDIs. It is equivalent to other ICS therapies at similar nominal doses. In Europe, it is recommended for once daily dosing. In the USA, it is recommended for twice daily dosing. It also has the same inhalation technique advantages as previously described for QVAR ${ }_{\mathbb{R}}$. Flunisolide is also available in some countries as an HFA-pMDI (Aerospan $\left.{ }^{\circledR}\right)$.

\section{Recommendations}

Prescribers should:

1) Know the devices that deliver drugs via HFA- versus CFCpMDIs (see table 2). 
TABLE 4 Detailed instructions on how to use pressurised metered-dose inhalers (pMDIs), breath-actuated (BA)-pMDIs, pMDIs with spacers, dry powder inhalers (DPIs), nebulisers and soft mist inhalers

pMDIs: for patients with good actuation-inhalation coordination

1) Shake four or five times if suspension formulation.

2) Take the cap off.

3) Prime the inhaler (refer to the PIL for specific instructions).

4) Exhale slowly, as far as comfortable (to empty the lungs).

5) Hold the inhaler in an upright position.

6) Immediately place the inhaler in the mouth between the teeth, with the tongue flat under the mouthpiece.

7) Ensure that the lips have formed a good seal with the mouthpiece.

8) Start to inhale slowly, through the mouth and at the same time press the canister to actuate a dose.

9) Maintain a slow and deep inhalation, through the mouth, until the lungs are full of air. This should take an adult 4-5 s.

10) At the end of the inhalation, take the inhaler out of the mouth and close the lips.

11) Continue to hold the breath for as long as possible, or up to $10 \mathrm{~s}$ before breathing out.

12) Breathe normally.

13) If another dose is required, repeat steps $4-12$.

\section{BA-pMDIs: for patients $\geqslant \mathbf{6}$ yrs old}

1-7) Same as above for pMDls alone.

8) Start to inhale slowly, through the mouth. The patient should sense that a dose has been released, either by taste or a noise when the dose is released (the noise is quiet for the Easi-Breathe $\mathbb{e}$ ).

9) Maintain a slow and deep inhalation, through the mouth, until the lungs are full of air. This should take a child $\sim 2-3 \mathrm{~s}$ and an adult $4-5 \mathrm{~s}$.

10-13) Same as above for pMDIs alone.

pMDI + spacer with facemask: for patients $\leqslant 3$ yrs old or anyone who cannot breathe consciously through the mouth

1-3) Same as above for pMDls alone.

4) Insert the mouthpiece of the pMDI into the open end of the spacer and ensure a tight fit. If a reverse flow spacer is used (table 6), insert the valve stem of the pMDI into the port on the mouthpiece of the spacer.

5) Place the facemask over the nose and mouth and be sure the fit is tight to the face.

6) Actuate one dose into the chamber of the spacer.

7) The patient should inhale and exhale normally into the spacer at least 10 times.

8) Take the facemask off the patient's face.

9) If another dose is required, repeat steps 1-8.

pMDI + spacer with mouthpiece: for patients $\geqslant 3$ yrs old (caregiver should determine if child can perform this technique correctly)

1-4) Same as above for spacer with facemask.

5) Place the mouthpiece of the spacer in the patient's mouth with the teeth over the mouthpiece and the lips sealed around it.

6) Actuate one dose into the chamber of the spacer.

7) Instruct the patient to inhale and exhale using normal (tidal) breaths into the spacer at least 5 times. With some spacers, the inhalations and exhalations can be monitored by observing the movement of the valves.

8) If another dose is required, repeat steps 4-7.

9) If ICSs are used, rinse mouth afterwards.

pMDI + spacer with mouthpiece: for patients $\geqslant \mathbf{6}$ yrs old (caregiver should determine if child can perform this technique correctly)

1-4) Same as above for spacer with facemask.

5) Place the mouthpiece of the spacer in the patient's mouth with the teeth over the mouthpiece and the lips sealed around it.

6) Instruct the child to exhale slowly, as far as comfortable (to empty their lungs).

7) Actuate one dose into the chamber of the spacer and start to inhale slowly through the mouthpiece. Some spacers will make a whistling noise if inspiration is too fast.

8) Maintain a slow and deep inhalation through the mouth, until the lungs are full of air. This should take a child $2-3 \mathrm{~s}$ and an adult $5 \mathrm{~s}$.

9) At the end of the inhalation, take the inhaler out of the mouth and close the lips.

10) Continue to hold the breath for as long as possible for up to $10 \mathrm{~s}$ before breathing out.

11) Breathe normally.

12) If another dose is required, repeat steps $1-11$.

13) If ICSs are used, rinse mouth afterwards.

\section{DPIs: for patients $\geqslant \mathbf{5 - 6}$ yrs old (caregiver should determine if child can perform this technique correctly)}

1) Take the cap off (some do not have a cap).

2) Follow the dose preparation instructions in the PIL.

3) Do not point the mouthpiece downwards once a dose has been prepared for inhalation because the dose could fall out.

4) Exhale slowly, as far as comfortable (to empty the lungs). Do not exhale into the DPI.

5) Start to inhale forcefully through the mouth from the very beginning. Do not gradually build up the speed of inhalation.

6) Continue inhaling until the lungs are full.

7) At the end of the inhalation take the inhaler out of the mouth and close the lips. Continue to hold the breath for as long as possible, or up to $10 \mathrm{~s}$. 


\title{
TABLE 4 Continued
}

\author{
8) Breathe normally. \\ 9) If another dose is required, repeat steps $1-8$.
}

Jet nebulisers: for patients of any age who cannot use a pMDI with a valved holding chamber, with or without a facemask, or if the drug is only available as nebuliser liquid

1) Assemble the tubing, nebuliser cup and mouthpiece (or mask).

2) Pour the medication solution into the nebuliser cup.

3) Do not exceed the fill volume recommended by the manufacturer.

4) Connect to power source; flow of $6-8 \mathrm{~L} \cdot \mathrm{min}^{-1}$, or compressor.

5) Place the mouthpiece in the mouth and close the lips around it (or cover the nose and mouth with an appropriate facemask).

6) Keep the nebuliser vertical during treatment.

7) Inhale and exhale using normal (tidal) breaths, with occasional deep breaths, until the nebuliser starts to sputter or no more aerosol is produced.

8) If the treatment must be interrupted, turn off the unit to avoid waste.

9) At the completion of the treatment, take the mouthpiece out of the mouth.

10) Dismantle and clean nebuliser following manufacturer's instructions.

11) With technology that differs from that of a traditional jet nebuliser, clinicians should thoroughly review operating instructions prior to patient use and instruction.

Mesh nebulisers: for use with drugs licensed with this type of nebuliser

1) Assemble the device according to the manufacturer's instructions.

2) Follow manufacturer's instructions to test the nebuliser function prior to the first use of a new device and after each cleaning to verify proper operation.

3) Pour the medication solution into the medication reservoir. Do not exceed the volume recommended by the manufacturer.

4) Turn on the power.

5) Hold the nebuliser in the position recommended by the manufacturer.

6) Put the mouthpiece into the mouth and close the lips around it.

7) Inhale and exhale using normal (tidal) breaths, with occasional deep breaths.

8) At the completion of the treatment, take the mouthpiece out of the mouth.

9) Clean nebuliser following the manufacturer's instructions.

Soft mist inhalers

Assemble and use the device according to the manufacturer's instructions.

PIL: patient information leaflet; ICSs: inhaled corticosteroids. See Appendix for all product/drug manufacturer details.

2) Know the differences between the HFA-beclomethasone pMDI formulations and their clinical relevance.

3) Specify the brand when prescribing beclomethasone HFApMDI, in countries where both $\mathrm{QVAR}_{\mathbb{}}$ and Clenil ${ }_{\Re}$ are available.

4) Know that the equivalence guidance is based on mean data and does not necessarily apply to individuals. Whenever a change is made in an ICS device, titration to the lowest effective ICS dose should be performed.

5) Instruct patients to adhere to the cleaning and priming instructions in the PIL.

6) Ensure that patients follow the inhalation techniques for pMDIs as recommended in table 4.

7) Instruct patients that they may not always sense or taste the drug entering their mouth from some of the new pMDI products. Nevertheless, if they follow the instructions, they should receive the appropriate dose of drug.

\section{Breath-actuated pressurised metered-dose inhalers}

BA-pMDIs that are currently available are the Autohaler ${ }^{\circledR}$ and Easi-Breathe ${ }^{\circledR}$. They were developed to overcome the commonly encountered problem of poor actuation-inhalation coordination with standard pMDIs [45]. The Autohaler® automatically actuates at inspiratory flow rates of $\sim 30 \mathrm{~L} \cdot \mathrm{min}^{-1}$ and the Easi-Breathe ${ }^{\circledR}$ actuates at $20 \mathrm{~L} \cdot \mathrm{min}^{-1}$. In one study, $<5 \%$ of patients were unable to achieve the threshold inspiratory flow rate required for actuation of the Autohaler ${ }_{\circledast}$ and there were fewer errors [46], compared with using conventional pMDIs [10]. As shown in table 2, salbutamol and beclomethasone are available as BA-pMDIs in Europe. In the USA, only pirbuterol is available. For patients with poor actuation-inhalation coordination, BA-pMDIs may improve lung deposition, compared with pMDIs alone [45].

\section{Recommendations}

Prescribers should:

1) Know that BA-pMDIs may be useful for patients who have actuation-inhalation coordination difficulty.

2) Instruct patients to be sure that they have triggered the dose during the inhalation. This is noticed by taste, sensation, or a noise that confirms dose emission. The noise from the EasiBreathe ${ }_{\circledast}$ is quiet and resembles a "whoosh" sound.

3) Ensure that patients follow the inhalation techniques for BApMDIs as recommended in table 4 .

4) Recognise that some oropharyngeal deposition still occurs with extra-fine QVAR ${ }_{\circledast}$ BA-pMDI and instruct patients to rinse their mouths out after inhaling. 
TABLE 5 Advantages and disadvantages of pressurised metered-dose inhalers (pMDIs), pMDIs with spacers, breath actuated (BA)-pMDls, nebulisers and dry powder inhalers (DPIs)

$\begin{array}{lll}\text { Type Advantages Disadvantages } & \text { Adval }\end{array}$

HFA-pMDIs (suspension and solution) Portable and compact.

Short treatment time.

No contamination risk.

High reproducibility between doses.

As above for pMDIs.

HFA-pMDIs (extra-fine particles)

\section{pMDI+spacers}

\section{BA-pMDIs}

Portable and compact. Many are multi-dose.

Some are single-dose with doses kept separately in sealed packages.

Breath-actuated, so no outside energy source, or propellant, is needed. With no propellant needed, it avoids the possible damaging effects of CFCs to Earth's ozone layer. Also, there is no need to coordinate actuation and inhalation, which is required with a pMDI.

Higher lung deposition and lower oropharyngeal deposition, compared with pMDIs that are used alone. (a)

coordination of actuation and

Reduced oropharyngeal deposition compared with a pMDI alone.

Improves lung deposition if this is poor with pMDI alone. Useful for maintaining efficient drug delivery during acute exacerbations

Can use tidal breathing if the spacer has a valve. Some spacers make a noise to indicate that the inhalation flow is too fast.

May be useful for patients who cannot coordinate inhalation and actuation; may be useful for the elderly.

Should not be used with a spacer or VHC
Coordination of actuation and inhalation needed.

Most patients inhale too fast.

Low lung deposition and high oropharyngeal deposition. Important to prime before use if new or not used in some time.

Must be kept upright during inhalation.

With most devices, the number of doses remaining is difficult to determine. Only one $\beta_{2}$-adrenergic agonist device has a dose counter (Ventolin $\mathbb{E}$ ) and it is only available in the USA. Seretide ${ }^{\circledR}$ and Symbicort $\mathbb{R}$ (combination drug devices) have dose counters. Symbicorte is only available in the USA.

Few drugs available as breath-actuated pMDIs. Important to prime before use if new, or not used in some time. so patients need to be instructed to inhale slowly.

Can only be used with a drug that is dispensed with the device; no substitutions.

Single-dose devices require repeat loading, which can lead to error. Two separate inhalations are required for each dose.

DPI delivery can result in high oropharyngeal deposition because a forceful inhalation is needed to aerosolise the particles.

Flow-dependent dose emission for some designs. Poor quality (or no) dose emitted if inspiratory flow is too slow.

Patients need to exhale into the room to functional residual capacity before inhaling from the DPI. Patients should not exhale into the device once the dose has been prepared for inhalation, or the dose could be blown out of the device. 
Type

Nebulisers

May be used at any age

Vibrating mesh nebulisers are portable and do not require an outside energy source.

Patient coordination not required.

May be used to dispense drugs that are not available for delivery by $\mathrm{pMDI}$ or DPI.

No propellant needed.

Breath-enhanced nebulisers, dosimetric nebulisers and vibrating mesh nebulisers are much less wasteful of drug than pneumatic jet nebulisers.

Dosimetric nebulisers deliver aerosol during inhalation only, over a proscribed time period, and turn off when dosing is complete.
Disadvantages

Patients need to inhale forcefully from the beginning. They should not gradually increase their speed of inhalation. Uncertainty of emitted dose during acute exacerbations. More expensive than pMDIs.

Must be upright when preparing the dose for inhalation

Must be kept upright or turned horizontally during inhalation.

Needs to be stored in a cool and dry place.

Pneumatic jet devices require an outside energy source and compressor

Treatment times can be long

Suspensions do not nebulise well.

Performance (i.e. emitted dose and particle size) varies significantly between devices.

With pneumatic jet nebulisers, drug can be lost to the surrounding environment during exhalation, exposing caregivers and other personnel to the drug.

Many pneumatic jet nebulisers are wasteful since a certain volume of solution cannot be aerosolised (i.e. dead volume)

There may be a risk of bacterial contamination if the device is not properly cleaned.

Newer devices (i.e. vibrating mesh nebulisers) are expensive.

HFA: hydrofluoroalkane; VHC: valved holding chamber; CFC: chlorofluorocarbon. See Appendix for all product/drug manufacturer details. Reproduced and modified from [9], with permission from the publisher.

\section{Spacers and valved holding chambers}

Table 6 lists the most commonly used spacers. Spacers are accessory devices to be used with pMDIs. They can be simple extension devices that increase the distance between the pMDI and oropharynx, thereby reducing orophayngeal deposition, or

\section{TABLE 6 Characteristics of commonly used spacers}

\begin{tabular}{|c|c|c|c|}
\hline Spacer ${ }^{\#}$ & Type & Valved & Anti-static \\
\hline Aerochamber Plus $₫$ & Small volume & Yes & No \\
\hline Aerochamber Max® & Small volume & Yes & Yes \\
\hline \multicolumn{3}{|c|}{ (Breathatec $\otimes$ in Australia) } & No \\
\hline Vortex@ & Small volume & Yes & Yes \\
\hline Volumatic $\circledast$ & Large volume & Yes & No \\
\hline Babyhaler@ & Large volume & Yes & No \\
\hline Ace $\otimes_{8}$ & Large volume/reverse flow & Yes & No \\
\hline Optihaler ${ }_{\circledast}$ & Large volume/reverse flow & No & No \\
\hline InspirEase & Opaque reservoir/reverse flow & No & No \\
\hline Microspacer ${ }_{\circledR}$ & Extension device & No & No \\
\hline Synchro-Breathe & Extension device & No & No \\
\hline
\end{tabular}

\#: not all devices are available in every country. See Appendix for all product/ drug manufacturer details. they can be more elaborate. Spacers that incorporate a one-way valve are VHCs. They allow patients to inhale a static cloud. VHCs overcome the issue of coordinating actuation with inhalation, and they increase pulmonary deposition in those subjects who do not have optimal coordination when actuating a pMDI [47-50]. Spacers and VHCs should not be used with BA-pMDIs.

Due to the reduced impaction in the oropharynx, spacers and VHCs are recommended for use with ICSs. Impaction in the oropharynx is also reduced by using the QVAR ${ }_{\mathbb{B}}$ HFA-pMDI (without a spacer) [38]. Nevertheless, since some oropharyngeal deposition may still occur, patients are advised to rinse their mouths out after inhaling an ICS with any of these devices. Changing the spacer in effect represents a change in the delivery system. With a change in spacer device, regular monitoring and titration of the ICS dose to the lowest effective dose is advised.

Although the shape and volume of spacers can vary greatly, they are generally grouped into two categories: 1) small volume (130-300 mL) and 2) large volume (600-800 mL). Some spacers incorporate a whistle that makes a sound if inspiratory flow is too fast. Training subjects to ensure that the whistle does not sound assists with developing an optimal inhalation technique. Some spacers incorporate a reverse-flow design to enhance small particle delivery to the patient. In these spacers, 
the flow of aerosolised medication is directed away from the patient's mouth upon actuation and is then directed back towards the mouth during inhalation.

Some pMDIs are licensed with a specific spacer. For example, HFA Seretide ${ }^{\circledR}$ is licensed with the Volumatic ${ }^{\circledR}$ or Aerochamber ${ }^{\circledR}$. Clenil ${ }_{\circledR}$ is licensed with the Volumatic ${ }^{\circledR}$ in the UK and with the Aerochamber ${ }^{\circledR}$ in the rest of Europe. QVAR $_{\circledast}$ HFA and Alvesco ${ }$ are licensed for use with the Aerochamber®.

A major disadvantage to spacers is that they are generally more bulky and less portable than a pMDI, and this often results in patients using the pMDI alone. Spacers also reduce the dose output from a pMDI to a variable extent. An additional source of variability in drug delivery with spacers is due to accumulation of an electrostatic charge on the plastic walls. Laboratory studies indicate that this electrostatic charge reduces spacer performance, such that the aerosol dose available for inhalation is reduced. This effect is most marked in newly purchased devices. The effect of electrostatic charge on the clinical outcome of an aerosolised medication is less clear and may affect some formulations more than others [51].

A number of "non-static" spacers have been developed. At present, there is a gradual country-by-country transition to the use of the Aerochamber ${ }^{\circledR}$, which is made of a non-static plastic material. Another option is the Vortex ${ }^{\circledR}$, which has an extremely thin metal layer on the inner surface of a plastic spacer that reduces static charge. The non-static metal Nebuchamber ${ }$ is currently off the market.

Because spacers are generally used for many months, they require periodic cleaning to prevent deterioration in the function of the valve and for hygienic reasons [52, 53]. The general advice for both newly purchased and previously used devices is to clean them by washing them with a low concentration of dishwashing liquid and allowing them to drip dry [54]. In this way, the plastic is coated with detergent, which reduces the electrostatic charge, decreases drug losses on spacer walls and promotes lung deposition [55].

The PILs of the different spacers are not consistent in terms of how often a spacer should be cleaned. Recommendations range in general from once a week to once a month. One study suggests that the effect of the detergent coating on electrostatic charge diminishes within 1 week [56]. It is not clear if this applies to all devices, so the recommendation is to follow the guidelines for cleaning found in the PIL for individual spacers. There is no consensus on whether spacers should be rinsed after cleaning with dishwashing liquid. Therefore, it is important to follow the recommendation found in the PIL for each spacer in terms of whether to rinse after washing or not.

Only one dose should be actuated into the spacer prior to each inhalation because multiple inhalations increase drug losses within the spacer as a result of increased turbulence [57]. Furthermore, the dose should be inhaled immediately after it is introduced into the spacer. Time delays reduce the emitted dose because particles have more time to deposit within the spacer [57].

\section{Recommendations}

Prescribers should:

1) Ensure that VHCs are used with pMDIs by infants and children and by patients with poor coordination or inhaler technique.

2) Ensure that spacers, or VHCs, are used when prescribing corticosteroids with pMDI to reduce oropharyngeal side-effects and absorption via the gut.

3) Advise patients to rinse their mouths out after inhaling a corticosteroid, even when using a spacer, VHC or QVAR ${ }_{\circledR}$ HFApMDI (with or without a spacer).

4) Know that spacers and VHCs should not be used with BA-pMDIs.

5) Ensure that patients follow the inhalation instructions for spacers as recommended in table 4 .

6) Instruct patients and caregivers to clean and use spacers according to the PILs.

7) Instruct patients and caregivers not to actuate more than once into a spacer prior to each inhalation and to inhale immediately after actuation with no time delay.

8) Know that with a change in spacer device, regular monitoring and titration of the ICS dose to the lowest effective dose is advised.

\section{Dry powder inhalers}

DPIs that are currently available are small and portable, and are breath-actuated, so patients do not have to coordinate actuation with inhalation. There are two basic types: 1 ) multidose DPIs, which contain many doses; and 2) single-dose capsule DPIs. There are also two versions of the multi-dose DPI: 1) those containing a bulk formulation in a reservoir, which is metered by the patient during use; and 2) premetered factory dispensed doses packaged inside blisters within the device. Table 2 shows that most DPIs are of the reservoir type.

All DPIs require the patient to prepare a dose prior to inhalation, as described in the PIL. Patients who do not perform these procedures correctly may receive no dose, irrespective of the inhalation manoeuvre they subsequently adopt. This type of critical error occurs frequently [58]. Some studies suggest that some patients have more problems using single-dose DPIs than multi-dose devices $[59,60]$.

Patients should be instructed to exhale into the room to functional residual capacity before inhaling through their DPI device. They should not exhale into the device, as that will result in blowing the dose out of the device. Failure to perform the proper exhalation manoeuvre before inhalation is the most common mistake made by DPI users [11]. Studies have also shown that dose emission is reduced when the DPI is exposed to extremely low and high temperature and humidity [61]. Therefore, DPIs should be stored in a cool dry place.

To ensure good powder flow during manufacture and consistency during dose metering, all DPIs are formulated with their drug particles attached to a carrier or as agglomerates in the form of pellets. To facilitate lung deposition, drug particles are de-agglomerated during inhalation. This is achieved 
by the creation of turbulent energy inside the DPI. The turbulent energy is the product of the patient's inhalation flow multiplied by the DPI's resistance. For this reason, all DPIs that are currently available are classified as passive devices. Increasing the inspiratory flow is generally associated with improved performance for a given device [62].

Different DPIs do not have the same internal resistance to airflow and range from low to high resistance $[62,63]$. This resistance means that patients have to inhale deeply and forcefully when using a DPI in order to receive the correct dose. Failure to inhale in this way is another common error when patients use their DPIs [11]. The resistance of a DPI can be classified with respect to the inhalation flow required to produce a pressure drop of $4 \mathrm{kPa}$. This value was chosen because it is the one recommended by pharmacopoeias for the in vitro characterisation of the dose emitted from a DPI. A device that is characterised as having a low resistance requires an inspiratory flow of $>90 \mathrm{~L} \cdot \mathrm{min}^{-1}$ to produce this pressure drop. A medium-resistance device requires $60-90 \mathrm{~L} \cdot \mathrm{min}^{-1}$. A medium/high-resistance device requires $50-60 \mathrm{~L} \cdot \mathrm{min}^{-1}$ and a high-resistance device requires $<50 \mathrm{~L} \cdot \mathrm{min}^{-1}[62,63]$. Table 2 presents the resistances of most DPI devices $[62,63]$. Patients will inhale faster through a low-resistance device [63]. However, because the internal energy in a DPI will be the same whether a patient inhales slowly through a DPI with a high resistance, or inhales quickly through a DPI with a low resistance, de-aggregation of the powder will also be the same [63]. For this reason, it is not valid to compare devices or classify them with respect to flow $[62,63]$. DPIs with a high resistance tend to produce greater lung deposition than those with a lower resistance $[62,63]$, but the clinical significance of this is not known. Furthermore, as the inhalation flow increases, deposition in the central airways will increase and distribution uniformity throughout the airways will decrease [17].

Figure 2 shows two possible patient inhalation profiles [64]. Both profiles attain the same peak inhalation flow, but one starts with a fast inhalation (i.e. fast acceleration rate) and the other gradually speeds up its flow (i.e. slow acceleration rate). It has been shown that de-agglomeration of particles takes

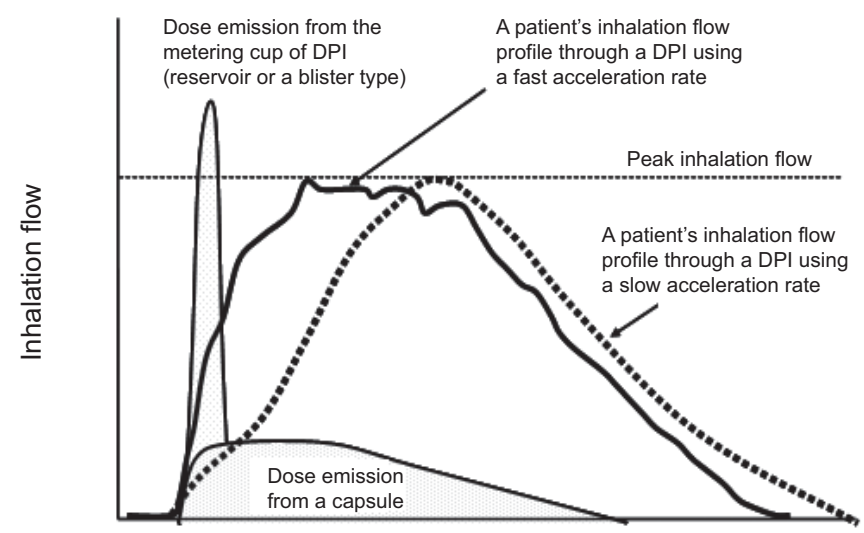

Time post start of inhalation

FIGURE 2. The relationship between dose emission from a dry powder inhaler (DPI) and the patient's inhalation. Reproduced and modified from [64] with permission from the publisher. place inside the device before the metered dose leaves the DPI and is increased if the acceleration is fast at the start of inhalation [65]. Thus, the FPD will be greater and the MMAD smaller when the initial acceleration rate of the inhalation flow is fast $[65,66]$. Hence patients should be instructed to inhale forcefully from the beginning of their inhalation.

Superimposed onto the two inhalation profiles in figure 2 are representations of when the dose is emitted from a capsule DPI and from a reservoir- or blister-type DPI. Clearly, the dose is emitted earlier during inhalation from the reservoir- or blistertype DPI, compared with the capsule DPI. For this reason, inhalation volume becomes important for patients using DPIs with capsules, and patients should repeat the inhalation to ensure that they receive the full dose.

Each DPI has a minimum threshold energy below which deagglomeration is inefficient, resulting in a reduced emitted dose with a high MMAD and small FPD. Below the minimum threshold energy, the patient will receive no, or very little, therapeutic effect from the drug. For example, it has been shown that the Turbuhaler ${ }^{\circledR}$ provides some clinical effect at low flows [67], but the minimum flow is around $30 \mathrm{~L} \cdot \mathrm{min}^{-1}$ and the optimal flow for this device is around $60 \mathrm{~L} \cdot \mathrm{min}^{-1}$. The Novolizer ${ }_{\circledR}$ is designed not to release its dose below an inspiratory flow rate of $35 \mathrm{~L} \cdot \mathrm{min}^{-1}$ [68]. Another dose cannot be metered until this threshold has been overcome. The Easyhaler ${ }_{\circledR}$ [69] and Clickhaler ${ }_{\circledR}$ [70] have both been shown to be effective at low-inhalation flows. For the Diskus ${ }^{\circledR}$ [71] and Handihaler ${ }^{\circledR}$ [72], the minimum inhalation flow is probably $30 \mathrm{~L} \cdot \mathrm{min}^{-1}$. For the Aerolizer ${ }^{\circledR}$, it is probably $>60 \mathrm{~L} \cdot \mathrm{min}^{-1}[73]$.

Studies have shown that young (preschool) children with asthma [74] and patients with COPD [75] may have problems achieving minimum flows through some DPIs, and that inhalation flow is reduced during acute exacerbations [76]. No manufacturer has stated the minimum flow for their DPI, although it is clear that this information is needed.

\section{Recommendations}

Prescribers should:

1) Refer to the inhalation instructions in the PIL and as described in table 4 .

2) Ensure that the patient is aware of the dose-preparation instructions in the PIL.

3) Ensure that the patient understands that they should exhale into the room to functional residual capacity before inhaling from their DPI.

4) Instruct the patient that they should not exhale into the DPI device before inhalation.

5) Instruct the patient to inhale forcefully from the beginning. They should not gradually increase their speed of inhalation.

6) Instruct the patient to inhale each dose as deeply as they can and to continue to inhale for as long as possible.

7) Instruct the patient that for single-dose capsule DPIs, they should perform two separate inhalations for each dose. 


\section{Nebulisers}

Nebulisers convert solutions and suspensions into small droplets. Solutions are comprised of drug dissolved in a carrier liquid, whereas suspensions are comprised of solid drug particles suspended in the carrier liquid. An advantage of using nebulisers includes their ability to aerosolise high doses of drugs that are not available with DPIs or pMDIs. In addition, many nebulisers come with facemasks, meaning they can be used by patients $<2$ yrs old, the elderly and those with severe respiratory distress.

\section{Pneumatic or jet nebulisers}

Pneumatic or jet nebulisers use compressed gas flow to entrain liquid from a reservoir and break the liquid into small droplets by means of baffles. The particle size distribution of the aerosol leaving the device is determined by the design of the baffle and the flow through the device. These nebulisers are relatively inefficient, compared with the newer devices described below. Despite their inefficiency, they are still widely used. For a detailed description of these systems, refer to the ERS guidelines on nebulisers published in 2001 [77].

When these nebulisers are employed in the home, their performance is dependent on the choice of compressor used to drive the nebuliser [78, 79]. Some nebuliser manufacturers specify the compressors that have been tested with their product.

\section{Breath-enhanced jet nebulisers}

Breath-enhanced jet nebulisers (e.g. the PARI LC ${ }_{\circledast}$ Plus, Ventstream ${ }^{\circledR}$ and the NL9M) increase output by raising airflow through the device during inhalation. Breath-enhanced nebulisers are relatively more efficient and deliver drug faster than traditional jet nebulisers.

\section{Dosimetric jet nebulisers}

Dosimetric jet nebulisers are also more efficient than traditional jet nebulisers. The breath-actuated AeroEclipse ${ }^{\circledR}$ generates aerosol during inhalation only, eliminating waste during exhalation. The AKITA ${ }_{\circledast}$ system controls the entire inhalation manoeuvre of the patient by applying a positive pressure delivered with a computer-controlled compressor. It can be used with conventional jet nebulisers and has been shown to improve aerosol delivery efficiency, with up to $60 \%$ deposition in the lung periphery of patients with COPD [80]. Such computer-controlled systems cost significantly more than traditional nebuliser delivery systems alone.

\section{Ultrasonic nebulisers}

Ultrasonic nebulisers transmit sound waves, generated by vibrating a piezoelectric crystal at high frequency $(>1 \mathrm{MHz})$, to the surface of the drug solution to be nebulised where the droplets are formed. Although ultrasonic nebulisers can nebulise solutions more quickly than pneumatic jet nebulisers, they are not suitable for suspensions and the piezoelectric crystal can heat and inactivate protein drugs such as dornase alfa [81, 82].

\section{Vibrating mesh nebulisers}

Vibrating mesh devices are either active or passive systems. In active devices (e.g. Aeroneb ${ }_{\circledR}$ Go and Pro devices, and eFlow $₫$ ), the aperture plate vibrates at a high frequency and draws the solution through the apertures in the plate. In passively vibrating mesh devices (e.g. MicroAir ${ }_{\circledR}$ and $\mathrm{I}_{-}$-neb ${ }_{\circledR}$ adaptive aerosol delivery (AAD) system), the mesh is attached to a transducer horn and vibrations of the piezoelectric crystal that are transmitted via the transducer horn force the solution through the mesh to create an aerosol.

The eFlow ${ }^{\circledR}$ is designed to be used with either a very low residual volume to reduce drug waste, or with a relatively large residual volume, so that it can be used instead of conventional jet nebulisers with the same fill volume.

The I-neb® AAD pulses medication delivery into $50-80 \%$ of each inspiration, based on an average of the last three breaths [83]. This device provides feedback to the patient regarding dose delivery and also incorporates software that can be used to monitor patient adherence.

Vibrating mesh devices have a number of advantages over other nebuliser systems. They are very efficient and quiet, and are generally portable, since they operate as effectively when using batteries or electricity. However, they are also currently significantly more expensive than other types of nebulisers, and they require a significant amount of maintenance and cleaning after each use to prevent build up of deposit and blockage of the apertures, especially when suspensions are aerosolised, and to prevent colonisation by pathogens. They are currently most widely used for the treatment of patients with CF. However, they are being developed for other uses, such as the delivery of vaccines, and they can also nebulise liposomal formulations [84-86] and proteins [87].

The performance of nebulisers can vary substantially. These differences may not be clinically significant when used to deliver bronchodilators, since these drugs have a wide therapeutic index. However, when delivering drugs with narrow therapeutic indices, it is important to choose a device that has been shown to be clinically effective. For this reason, new nebulised medications are increasingly being licensed with clear recommendations as to their use with specific nebulisers. Licensing drugs for delivery with specific nebulisers should reduce the potential for substantial variation in delivered dose due to alterations in the delivery system.

\section{Facemasks and mouthpieces}

Generally, mouthpieces are employed during nebuliser delivery. However, facemasks may be necessary for treatment of acutely dyspnoeic patients or uncooperative patients, such as infants and toddlers. The facemask is not just a connector between the device and the patient. Principles of mask design are different depending on the device. For example, a VHC with facemask must have a tight seal to achieve optimal lung deposition [88]. In contrast, the facemask for a nebuliser should not incorporate a tight seal, but should have vent holes to reduce deposition on the face and in the eyes $[89,90]$. Improvements in facemask design provide greater inhaled mass while reducing facial and ocular deposition [91].

Often, when a patient does not tolerate the facemask, practitioners employ the "blow-by" technique, which simply directs the aerosol towards the nose and mouth with the mouthpiece. However, there is no data to indicate that this is an effective method for delivering aerosol to the lungs, and a National 
Institutes of Health (NIH) expert panel recently indicated that the use of this technique is not appropriate [92].

\section{Recommendations}

Prescribers should:

1) Choose a nebuliser based on the recommendations found in the PIL for the drug that is being prescribed.

2) Choose a compressor that has been tested with the prescribed nebuliser brand.

3) Know that a jet nebuliser treatment should be stopped once the nebuliser starts sputtering.

4) Use an appropriate facemask when a mouthpiece is unsuitable.

5) Not use the blow-by technique.

6) Instruct patients that they need to clean their nebulisers after each use according to the manufacturer's directions.

7) Instruct patients that they should be careful not to touch the mesh when cleaning vibrating mesh nebulisers, as this could damage the unit.

8) Instruct patients that they should follow the manufacturer's recommendations for when to purchase a new nebuliser.

\section{Soft mist inhalers}

Currently, there is only one commercially available soft mist inhaler: the Respimat ${ }_{\mathbb{R}}$ Soft Mist ${ }^{\mathrm{TM}}$ Inhaler. This inhaler is available in Germany for the delivery of the combination of fenoterol and ipratropium bromide (50 and $20 \mu \mathrm{g}$ per puff, respectively). In Germany, and many other countries, it is available for the delivery of tiotropium bromide, $2.5 \mu \mathrm{g}$ per puff. The Respimat ${ }^{\circledR}$ Soft Mist ${ }^{\mathrm{TM}}$ Inhaler atomises the drug solution using mechanical energy imparted by a spring. When the spring is released, the solution is forced through an extremely fine nozzle system $[93,94]$. This produces a fine mist that is slow moving, leading to lower deposition in the mouth and throat and relatively high lung deposition (i.e. 39\%) [95-97].

\section{CHOICE OF DRUG-DEVICE COMBINATIONS TO USE AT HOME}

The device options and drugs for treating asthma and COPD at home are summarised in table 2. Drugs include bronchodilators, corticosteroids and combination formulations. The effectiveness of these drugs has been reviewed in detail [1-3, 92, 98]. These drugs can be administered using pMDIs, BApMDIs, DPIs, nebulisers or soft mist inhalers. In large part, the choice of delivery system is dependent on the class of drug chosen and by the capabilities of the patient. It is important to prescribe a device that the patient can and will use effectively at home. A spacer should be employed when ICSs are delivered by a pMDI, and patients should still be instructed to rinse out their mouth and gargle after each treatment to reduce the occurrence of oropharyngeal candidiasis and to minimise the systemic absorption of swallowed drug.

Patients with diseases other than asthma or COPD also utilise inhaled medications during treatment at home. These include patients with pulmonary arterial hypertension (PAH), HIVinfected (AIDS) patients and patients with CF. The most recent developments in drugs and devices to treat these patients are summarised below.

\section{Patients with pulmonary arterial hypertenstion}

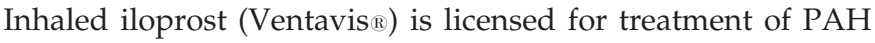
with the I-neb ${ }_{\circledR}$ AAD.

\section{HIV-infected (AIDS) or immunocompromised patients}

Inhaled pentamidine solution is an anti-infective agent that helps to treat or prevent pneumonia caused by the organism Pneumocystis carinii. The Respirgard II nebuliser is licensed to deliver NebuPent ${ }^{\circledR} 300 \mathrm{mg}$ for oral inhalation.

\section{Patients with cystic fibrosis}

Patients with CF must inhale one or more therapies at home several times per day. A recent review by FLUME et al. [4] examined the clinical evidence for each therapy and provides guidance for the prescription of these therapies. Aerosolised antibiotics have been advocated both for the eradication of the initial infection and for the suppression of the chronic infection due to Pseudomonas aeruginosa in patients with CF. During nebulisation of antibiotics, an expiration filter can be used to prevent contamination of the room and exposure of bystanders to potentially toxic drugs.

Tobramycin inhalation solution is an approved inhaled antibiotic used to treat $P$. aeruginosa in patients with $\mathrm{CF}$. TOBI ${ }_{\mathbb{R}}$ is licensed for inhalation with a PARI LC ${ }_{\circledR}$ Plus nebuliser and a DeVilbiss ${ }$ Pulmo-Aide ${ }$ air compressor. Bramitob ${ }_{\circledR}$ is licensed for administration with the PARI LC ${ }_{\circledR}$ Plus and the PARI TURBO Boy® compressor. In the summer of 2011, inhaled tobramycin will be licensed as a dry powder formulation for treatment of CF in some countries. Another inhaled antibiotic, inhaled colistin, is also recommended for treatment of CF. Colistin is recommended to be used with an appropriate jet nebuliser, such as the PARI LC $_{\circledR}$ Plus or the LC $C_{\circledR}$ Star, with either the PARI Master ${ }$ or a similar compressor. Inhaled colistin is also licensed for use with the I-neb ${ }_{\circledR}$ AAD in several countries. Similarly, in some countries, aztreonam inhalation solution is licensed for use with the $\mathrm{eFlow}^{\circledR}$ nebuliser as Cayston ${ }^{\circledR}$.

Nebulised hypertonic saline $(7 \% \mathrm{NaCl})\left(\right.$ Hyper-Sal $\left.{ }^{\mathrm{TM}}\right)$ has been shown to improve mucociliary clearance in patients with CF [99], and has been tested primarily with the PARI LC ${ }_{\mathbb{R}}$ Star nebuliser and PARI Proneb ${ }_{\circledR}$ compressor combination. Muco Clear ${ }(6 \% \mathrm{NaCl})$ and $\mathrm{Hyaneb}{ }^{\mathrm{TM}}(7 \% \mathrm{NaCl})$ are also available for mucociliary clearance. Both manufacturers recommend using a PARI nebuliser for administration.

Recombinant human DNase (rhDNase; dornase alfa) (Pulmozyme $_{\mathbb{R}}$ ) was developed to degrade free DNA that accumulates within the CF mucus, thereby improving the viscoelastic properties of airway secretions and promoting airway clearance [4]. Recommended nebuliser/compressor combinations for delivering rhDNase include the Hudson T Up-draft II ${ }_{\circledast}$ with Pulmo-Aide ${ }^{\circledR}$, the Marquest Acorn $\Pi_{\circledast}$ with Pulmo-Aide ${ }^{\circledR}$, the PARI LC ${ }_{R}$ Jet with PARI Proneb ${ }_{\circledR}$ compressor, the PARI BABY $_{\mathbb{B}}$ with PARI Proneb ${ }$, and the Durable Sidestream ${ }^{\circledR}$ with Mobilaire ${ }_{\circledR}$ or Porta-Neb®.

A detailed overview of new aerosol delivery devices for treating patients with CF has been written by KESSER and GELLER [100]. 


\section{Recommendations}

Prescribers should:

1) Know the many device options for treating patients at home (see table 2).

2) Choose the device that the patient can and will use.

3) Teach patients how to use the device correctly (see table 4 for use of pMDIs, BA-pMDIs, pMDIs with spacers, DPIs and nebulisers).

\section{CHOICE OF DRUG-DEVICE COMBINATIONS TO USE IN THE EMERGENCY ROOM AND HOSPITAL}

Pressurised metered-dose inhalers with spacers versus nebulisers to administer short-acting bronchodilators in the emergency room

Until recently, treating asthmatics and patients with COPD in the emergency room usually involved nebulisation of shortacting bronchodilators [1-3, 101, 102]. However, several studies have demonstrated similar efficacy for inhaled bronchodilators using pMDIs with spacers (pMDIs alone are not as effective), compared with nebulisers in emergency rooms in patients with non-life-threatening asthma and in patients with COPD with non-severe exacerbations [103-108]. To more closely match the dose administered by nebulisation, the number of puffs from the pMDI should be increased to between four and 10 puffs in the emergency room setting [104]. Administrations should be repeated as needed [104]. Potential advantages of this approach are cost savings, reduced time of administration and, more importantly, reinforcement of self-management messages.

\section{Nebulisers and patients with severe asthma and chronic obstructive pulmonary disease in the emergency room}

Nebulisers are indicated for patients with asthma and COPD who are undergoing severe exacerbations, especially those with alterations of consciousness. Oxygen is commonly employed as the driving gas for jet nebulisers in patients with severe asthma or acute exacerbations of COPD. It is advisable to avoid the uncontrolled use of oxygen in patients with severe COPD because of the risk of hypercapnia with high doses of oxygen [109, 110]. Such patients should be monitored for oxygen saturation and level of consciousness.

\section{Recommendations}

Prescribers should:

1) Know that, in non-life-threatening asthma and non-severe exacerbations of COPD, aerosolised $\beta_{2}$-adrenergic agonists can be administered effectively using a pMDI with spacer or VHC.

2) Use a nebuliser to administer $\beta_{2}$-adrenergic agonists whenever the patient cannot perform the correct inhalation manoeuvre with the pMDI and spacer.

3) Use nebulisers in patients with severe asthma or COPD, particularly those with consciousness alterations.

4) Use a driving gas flow of 6-8 $\mathrm{L} \cdot \mathrm{min}^{-1}$ for non-portable nebulisers.

5) Use oxygen as appropriate for the clinical condition.
Nebulisers and non-cystic fibrosis diseases in hospital

Hypertonic saline ( 3 or $5 \%$ ) seems to be the only agent to be clinically effective in bronchiolitis. It has been shown to significantly reduce the length of hospital stay and improve the clinical severity score in infants with acute viral bronchiolitis [111].

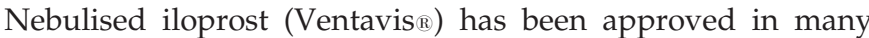
countries for New York Heart Association class III primary pulmonary hypertension. It is licensed for use with the I-neb ${ }_{R}$ AAD.

\section{CHOICE OF DRUG-DEVICE COMBINATIONS TO USE IN SPECIAL POPULATIONS \\ Children}

Aerosol therapy is often used for the treatment of pulmonary diseases in children. However, many of the paediatric indications are not evidence-based. A recent ERS Task Force guideline discusses recommended treatments for paediatric pulmonary diseases [112].

Many of the new devices also are not approved for use in children, and few studies are available to demonstrate efficacy in this population. However, according to the recently approved EMA guidelines, not all new drug-device combinations need to be tested clinically before approval for use in children is given. New guidelines on the requirements for clinical documentation for orally inhaled products can be found online [113]

The choice of device for children is affected by the child's cognitive ability. Children up to $\sim 3$ yrs of age are generally unable to adopt specific inhalation techniques and are therefore treated with nebulisers with a facemask [89], or with pMDIs with a VHC and facemask [114]. Refer to the inhalation instructions for nebulisers and pMDIs with spacers and facemasks provided in table 4. If the VHC+facemask combination does not achieve a tight fit over the child's nose and mouth, drug delivery to the lungs will be significantly reduced [88]. In a struggling child, it is difficult to achieve a good seal with the facemask and the inhaled dose is substantially reduced. If the child is screaming or crying, most of the inhaled drug deposits in the upper airway, not in the lungs [90].

If a child can be taught to use a mouthpiece, this should be encouraged, since mouthpiece breathing increases lung deposition, compared with facemask breathing [29]. Most (but not all) children can be taught to use a mouthpiece from $\sim 3$ yrs of age. When a child is inhaling through a mouthpiece attached to a nebuliser, place the mouthpiece in the mouth and instruct the child to close their lips around it. The child should then inhale and exhale using normal (tidal) breaths, with occasional deep breaths, until the nebuliser starts to sputter or no more aerosol is produced.

There are different ways to inhale from a pMDI+spacer using a mouthpiece. The easiest technique is inhaling from the spacer with normal, quiet breathing and this is useful when working with young and older children. With appropriate instruction, most children $>6$ yrs of age should be able to perform a "single-breath" technique with a pMDI+spacer [49]. This technique is described by ROLLER et al. [49] and appears to improve lung deposition of $\mathrm{QVAR}_{\mathbb{B}}$, compared with normal quiet breathing in older children. An experienced 
individual should instruct the child and caregiver how to perform these techniques and should check to determine whether the child is able to perform it correctly. Refer to the inhalation instructions for spacers with a mouthpiece in table 4 . If compliance with a pMDI and spacer is an issue for a child $>6$ yrs of age, most of these children (but not all) should be able to produce the forceful inhalation that is required to use a DPI [11]. Refer to the inhalation instructions for DPIs in table 4 .

In general, a pMDI+spacer is often the cheapest option for aerosol therapy. However, many school-age children will not use the spacer and, therefore, fail to deliver adequate amounts of drug to the lungs. In this context, a DPI may be the best option, although they are not intrinsically "superior" to the pMDI + spacer and are more expensive.

As previously mentioned, nebulisers can be used to deliver aerosols of formulations that cannot be administered as an aerosol with either pMDIs or DPIs. However, the new mesh nebulisers are an expensive option, and cheaper, pneumatic and breath-enhanced devices are more time-consuming and therefore less tolerated than a pMDI+spacer combination that incorporates a facemask in young children.

Several studies have demonstrated similar efficacy for inhaled $\beta_{2}$-adrenergic agonists using pMDIs with spacers (pMDIs alone are not as effective), compared with nebulisers in emergency rooms in children with non-life-threatening asthma [104, 114]. As is the case in adults with asthma, the number of puffs from the pMDI should be increased to between four and 10 puffs in the emergency room setting to more closely match the dose administered by nebulisation [114]. Administrations should be repeated as needed [104].

\section{Recommendations}

Prescribers should:

1) Match the device to the patient's capability to perform the specific inhalation manoeuvres recommended for the device.

2) Choose a device that has performance-capability information for the specific age group of the patient.

3) Refer to table 4 for inhalation instructions.

4) Choose a combination nebuliser with a facemask, or a pMDI with a VHC and facemask, for children $<3$ yrs of age.

5) Maximise cooperation to optimise lung deposition in young children.

6) Teach children who are 3-6 yrs old to breathe tidally from a spacer using a mouthpiece, if they can perform this technique correctly.

7) Teach children who are $\geqslant 6$ yrs old to adopt a single, slow maximal inhalation and breath-hold while using a pMDI+ spacer with a mouthpiece, if they can perform this technique correctly.

8) Know that in the emergency room, $\beta_{2}$-adrenergic agonists can be administered to children with mild and moderate exacerbations of asthma by means of a pMDI+spacer or nebuliser.

\section{The elderly}

Those prescribing aerosol treatment for the elderly face similar problems to those which are confronted by physicians who treat children. Cognitive decline means that the more complex manoeuvres may be challenging for many elderly patients. The situation is compounded by dexterity issues. Once again, the clinician is obligated to prescribe a delivery system that a patient can and will use effectively. For many with limited abilities to adopt complex inhalation manoeuvres, the simplicity of a jet nebuliser may be a necessary compromise.

\section{Intubated and mechanically ventilated patients}

Aerosols can be administered to intubated and mechanically ventilated patients by pMDI and in-line spacer, or by nebuliser. The efficacy of pMDI delivery during mechanical ventilation is dependent on the actuation of the pMDI through a spacer or holding chamber that is tightly inserted into the inspiratory limb side of the ventilator circuit, at $\sim 15 \mathrm{~cm}$ from the endotracheal tube $[115,116]$. In adult patients, a tidal volume $\geqslant 0.5 \mathrm{~L}$ guarantees drug delivery to the lower respiratory tract $[117,118]$.

The rate of aerosol production and the characteristics of the aerosol generated by a nebuliser differ between devices [119] and depend on ventilator mode [120], pulmonary mechanics [120], inspiratory flow rate [121] and distance from the endotracheal tube [122].

The efficiency of aerosol delivery with both pMDIs and nebulisers is reduced by humidity in the ventilator circuit [123]. In contrast, aerosol delivery is increased with both pMDIs and nebulisers when helium-oxygen mixtures are used in place of air or air-oxygen mixtures to ventilate the patient [124], and both techniques have proven to be clinically effective [125].

Aerosolised albuterol/salbutamol at a dose of $2.5 \mathrm{mg}$ with a nebuliser [126], or four puffs $(400 \mu \mathrm{g})$ with a pMDI and spacer [116], produces significant bronchodilator effects in mechanically ventilated patients with COPD. Albuterol/salbutamol should be repeated every 3-4 h [115]. Nebulised fenoterol at a dose of $0.4 \mathrm{mg}$ was found to be effective in intubated COPD patients [127]. Both pMDIs and jet nebulisers are equally effective for bronchodilator administration in mechanically ventilated patients, but pMDIs have the advantages of convenience, lower cost and reduced risk of damaging flow sensors.

In mechanically ventilated acute respiratory distress syndrome patients, nebulised prostacyclin and prostaglandin $\mathrm{E}_{1}$ are as effective as nitric oxide in improving oxygenation and haemodynamics [128, 129].

Newer-generation vibrating mesh nebulisers have been designed specifically for use during mechanical ventilation and have been shown to be efficient for drug delivery in bench studies. These devices are currently under investigation and little clinical information is available.

\section{Recommendations}

Prescribers should:

1) Know that aerosols can be administered to intubated and mechanically ventilated patients by pMDI and in-line spacer, or by a nebuliser designed for use during mechanical ventilation. 
2) Know that aerosolised albuterol/salbutamol at a dose of $2.5 \mathrm{mg}$ with a nebuliser, or four puffs $(400 \mu \mathrm{g})$ with a pMDI, or nebulised fenoterol at a dose of $0.4 \mathrm{mg}$ have significant bronchodilator effects.

3) Know that higher doses produce negligible additional therapeutic advantage.

\section{Patients on noninvasive mechanical ventilation}

Aerosols can be administered to patients receiving noninvasive mechanical ventilation (NIMV) by pMDI and spacer with facemask, or by nebuliser with facemask. Based on the currently available literature [130], the recommended technique for using a pMDI in patients receiving NIMV is to: 1) minimise leaks in the mask and/or circuit; 2) place a cylindrical spacer (volume $\sim 140 \mathrm{~mL}$ ) between the circuit and mask; 3) shake the pMDI canister well and place it in the adapter of the spacer chamber; 4) actuate pMDI at the beginning of inspiratory airflow from the ventilator; 5) repeat actuations after an interval of $\geqslant 15 \mathrm{~s}$; and 6) monitor the patient and assess the clinical response. The recommended technique for nebulisers is to: 1) minimise leaks in the mask and or circuit; 2) fill the nebuliser with drug solution up to optimal fill volume (4-6 mL); 3) place the nebuliser in an upright position between the circuit and mask; 4) operate the nebuliser with a gas flow of $6-8 \mathrm{~L} \cdot \mathrm{min}^{-1}$; $5)$ tap the nebuliser periodically until it begins to sputter or stops producing aerosol; 6) remove the nebuliser from the circuit, rinse with sterile water, air dry and store in a clean space; and 7) monitor the patient and document clinical response.

The position of the leak port in the circuit influences the efficiency of drug delivery from a nebuliser during noninvasive ventilation, but it does not influence the efficiency of drug delivery from pMDIs [131]. Nebuliser efficiency is higher with the leak port in the circuit, as compared with a leak port in the facemask [132]. Furthermore, the findings of CALVERT et al. [132] suggest that a nebuliser placed between the ventilator and leak port (ventilator, nebuliser, leak port, facemask) performs with higher efficiency than placement of the nebuliser between the leak port (ventilator, leak port, nebuliser, facemask).

\section{Recommendations}

Prescribers should:

1) Know that aerosolised medications can be administered during NIMV either by pMDI and a spacer with facemask, or with a nebuliser and facemask.

2) Know the proper technique for using a pMDI and spacer, or nebuliser, during NIMV.

3) Know where to position the nebuliser in relation to the leak port in the circuit.

\section{THE FUTURE}

Developments in inhaled therapy will lead to novel drugs using existing delivery systems, existing drugs delivered in novel delivery systems, and new drugs in novel delivery systems. The increasingly prescriptive approach of regulators relating to drug-device combinations should remove much of the variability that has been evident in the past due to the choice of nebulisers and compressors. Prescribers must continually update their understanding of the strengths and weaknesses of any delivery systems they choose to prescribe. Recommendations for future research in this field are found in the study by HAUGHNEY et al. [133].

\section{CONCLUSIONS}

The use of an inhaler by a patient has a strong scientific basis that is related to the dose of drug that is deposited into the lungs. Because the dose delivered to the lungs is so dependent on the correct use of the delivery system, those who prescribe inhaler devices should ensure that patients can and will use them correctly. This requires that prescribers: know the devices that are currently available to deliver the prescribed drugs and the various techniques that are appropriate for each device; are able to evaluate the patient's inhalation technique to be sure they are using the devices properly; and ensure that the inhalation method is appropriate for each patient. This Task Force report provides considerable information about the correct use of these devices, including detailed information about drugs that are currently available for delivery with specific devices, detailed instructions on how to use specific inhalers, guidelines for how to determine what device is best for your patient at home and in hospital, as well as numerous recommendations to ensure that your patient understands how to use the device you prescribe.

It should be stressed that once a patient is familiar and stabilised on one type of inhaler, they should not be switched to new devices without their involvement and without followup education on how to use the device properly. A recent study has shown that asthma control deteriorates if an inhaler is substituted for a different device at the prescribing or dispensing stage without involving the patient [134]. Prescribers should be especially vigilant on this point in order to avoid changes to the type of device their patients receive through the pharmacy.

\section{STATEMENT OF INTEREST}

Statements of interest for H.M. Janssens, F.H.C. de Jongh, S.G. Devadason, R. Dhand, M.L. Everard, I. Horvath and H. Chrystyn can be found at www.erj.ersjournals.com/site $/ \mathrm{misc} /$ statements.xhtml

\section{APPENDIX}

Manufacturer details for all products/drugs mentioned in this Task Force Report are as follows (in alphabetical order). Accuhaler ${ }_{\circledR}$ : GlaxoSmithKline, Uxbridge, UK. Ace®: DHD Healthcare Corp., Wampsville, NY, USA. Aerochamber Max®: Trudell Medical International, London, ON, Canada.

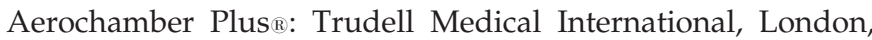
ON, Canada. AeroEclipse ${ }^{\circledR}$ : Trudell Medical International, London, ON, Canada. Aerolizer ${ }^{\circledR}$ : Novartis International AG, Basel, Switzerland. Aeroneb ${ }_{\circledR}$ Go and Pro: Aerogen Ltd, Galway, Ireland. Aerospan $₫$ : Forest Pharmaceuticals Inc., St Louis, MO, USA. Airomir ${ }^{\circledR}$ : TEVA Pharmaceutical Industries Ltd, Tikva, Israel. AKITA®: Activaero GmbH, Gemuenden,

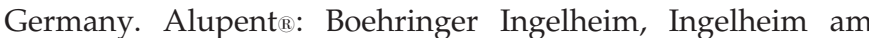
Rhein, Germany. Alvesco®: Nycomed, Zurich, Switzerland. Atimos®: Chiesi Farmaceutica SPA, Parma, Italy. Atrovent ${ }^{\circledR}$ : Boehringer Ingelheim, Ingelheim am Rhein, Germany. Autohaler®: TEVA Pharmaceutical Industries Ltd, Tikva, Israel. Babyhaler®: GlaxoSmithKline, Uxbridge, UK. Bramitob®: Chiesi Farmaceutica SPA, Parma, Italy. Cayston ${ }^{\mathrm{TM}}$ : Gilead, 
Foster City, CA, USA. Clenil ${ }_{\circledR}$ : Chiesi Farmaceutica SPA, Parma, Italy. Clickhaler ${ }_{\AA}$ : Mylan, Canonsburg, PA, USA. Combivent ${ }^{\circledR}$ : Boehringer Ingelheim, Ingelheim am Rhein, Germany. Cyclohaler®: TEVA Pharmaceutical Industries Ltd, Tikva,

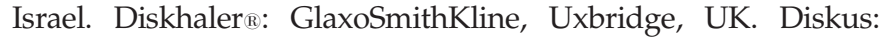
GlaxoSmithKline, Uxbridge, UK. Durable Sidestream®: Philips Healthcare, Best, The Netherlands. Easi-Breathe ${ }^{\circledR}$ : TEVA Pharmaceutical Industries Ltd, Tikva, Israel. Easyhaler®: Orion Corp., Espoo, Finland. eFlow $\mathbb{R}$ : Pari GmbH, Starnberg, Germany. Flixotide ${ }^{\circledR}$ : GlaxoSmithKline, Uxbridge, UK. Flovent ${ }^{\circledR}$ : Glaxo SmithKline, Uxbridge, UK. Foradil $₫$ : Novartis International AG, Basel, Switzerland. Fostair ${ }^{\circledR}$ : Chiesi Farmaceutica SPA, Parma, Italy. Foster ${ }_{\mathbb{R}}$ : Chiesi Farmaceutica SPA, Parma, Italy. Fostex ${ }_{\mathbb{R}}$ : Chiesi Farmaceutica SPA, Parma, Italy. Handihaler ${ }^{\circ}$ : Boehringer Ingelheim $\mathrm{GmbH}$, Ingelheim am Rhein, Germany. Hudson $\mathrm{T}$ Up-draft $I_{\circledast}$ : Hudson RCI, Research Triangle Park, NC, USA. Hyaneb $^{\text {TM}}$ : Praxis Pharmaceuticals, Madrid, Spain. Hyper-Sal ${ }^{\text {TM}}$ : PARI GmbH, Starnberg, Germany. IN-Check Dial®: Clement Clarke International Ltd, Harlow, UK. I-neb®: Philips Healthcare, Best, The Netherlands. Innovair ${ }^{\circledR}$ : Chiesi Farmaceutica SPA, Parma, Italy. InspirEase ${ }^{\circledR}$ : Key Pharmaceuticals, Kenilworth, NJ, USA. Maghaler®: HGB Pharma Service GmbH, Mainz, Germany. Marquest Acorn II®: Parquest Medical Inc., Englewood, CO, USA. Maxair ${ }$ Autohaler: Graceway Pharmaceuticals LLC, Bristol, TN, USA. MicroAir ${ }_{\circledR}$ : Omron, Kyoto, Japan. Microspacer®: RDS, Chelmsford, MA, USA. Mobilaire ${ }^{\circledR}$ : Invacare Corporation, Elyria, OH, USA. MucoClear®: PARI GmbH, Starnberg, Germany. NebuPent $\mathbb{R}$ : APP Pharmaceuticals LLC, Schaumburg, IL, USA. NL9M Atomisor: La Diffusion Technique Francaise, Saint-Etienne, France. Novolizer ${ }^{\circledR}$ : MEDA AB, Solna, Sweden. Optichamber®: Philips Healthcare, Best, The Netherlands. Optihaler ${ }^{\circledR}$ : Philips Healthcare, Best, The Netherlands). PARI BABY $_{\circledast}$, PARI LC ${ }_{\circledR}$ Jet, PARI LC ${ }_{\circledR}$ Plus, PARI LC ${ }_{\circledR}$ Star, PARI Master ${ }^{\circledR}$, PARI Proneb ${ }$ and PARI TURBO Boy®: PARI GmbH, Starnberg, Germany. Perforomist $₫$ : Dey Pharma, Basking Ridge, NJ, USA. Porta-Neb®: Philips Healthcare, Best, The Netherlands. ProAir ${ }_{\circledR}$ TEVA Pharmaceutical Industries Ltd, Tikva, Israel. Promixin $₫$ : Profile Pharma, Chichester, UK. Proventil®: Merck \& Co., Whitehouse Station, NJ, USA. Pulmicort ${ }$ : AstraZeneca Plc, London, UK. Pulmicort Respules ${ }^{\circledR}$ : AstraZeneca Plc, London, UK. Pulmo-Aide ${ }_{\mathbb{R}}$ : DeVilbiss Healthcare, Somerset, PA, USA. Pulmozyme ${ }^{8}$ : Roche, Basel, Switzerland. Pulvinal ${ }_{\AA}$ : Chiesi Farmaceutica SPA, Parma, Italy. QVAR: TEVA Pharmaceutical Industries Ltd, Tikva, Israel. Respimat ${ }^{\circledR}$ : Boehringer Ingelheim, Ingelheim am Rhein, Germany. Respimat ${ }^{\circledR}$ Soft Mist ${ }^{\mathrm{TM}}$ Inhaler: Boehringer Ingelheim, Ingelheim am Rhein, Germany. Respirgard II: Vital Signs Inc., Totowa, NJ, USA. Seretide ${ }$ : GlaxoSmithKline, Uxbridge, UK.

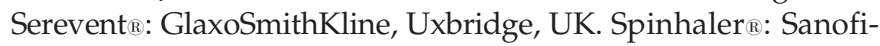
Synthelabo Inc., St Louis, MO, USA. Spiromax®: TEVA Pharmaceutical Industries Ltd, Tikva, Israel. Symbicort ${ }^{\circledR}$ : AstraZeneca Plc, London, UK. Synchro-Breathe ${ }^{\circledR}$ NeoInhalation Technologies Limited, Manchester, UK. Tilade ${ }_{\mathbb{R}}$ : Sanofi-Aventis, Surrey, UK. TOBI ${ }_{\circledR}$ : Novartis AG, Basel, Switzerland. Turbuhaler ${ }^{\circ}$ AstraZeneca Plc, London UK. Twisthaler®: Merck \& Co., Whitehouse Station, NJ, USA. Ventavis ${ }_{\mathbb{R}}$ : Bayer AG, Leverkusen, Gemany). Ventolin ${ }^{\circledR}$ : GlaxoSmithKline, Uxbridge, UK. Ventstream ${ }^{\circledR}$ : Philips Healthcare, Best, The Netherlands. Volumatic ${ }^{\circledR}$ : GlaxoSmithKline, Uxbridge, UK. Vortex®: PARI GmbH, Starnberg, Germany.
Xopenex®: Sunvovion Pharmaceuticals Inc., Marlborough, MA, USA.

\section{ACKNOWLEDGEMENTS}

The authors affiliations are: B.L. Laube, Dept of Paediatrics, School of Medicine, Johns Hopkins University, Baltimore, MD, USA; H.M. Janssens, Paediatric Respiratory Medicine, Erasmus MC/Sophia Children's Hospital, Rotterdam, the Netherlands; F.H.C. de Jongh, Pulmonology, Medisch Spectrum Twente, Enschede, the Netherlands; S.G. Devadason, School of Paediatrics and Child Health, University of Western Australia, Perth, Western Australia, Australia; R. Dhand, Internal Medicine, University of Missouri, Columbia, MO, USA; P. Diot, Pneumologie, INSERM U618, Hôpital Bretonneau, Tours, France; M.L. Everard, Respiratory Medicine, Sheffield Children's Hospital, Sheffield, UK; I. Horvath, Dept of Pulmonology, Semmelweis University, Budapest, Hungary; P. Navalesi, Ospedale Sant'Andrea Anaesthesia and Intensive Care, Universitá del Piemonte Orientale "A. Avogadro", Vercelli, Italy; T. Voshaar, Pulmonology, Allergy, Sleep Medicine, Interdisciplinary Lung Centre, Krankenhaus Bethanien Moers, Moers, Germany; H. Chrystyn, Division of Pharmacy and Pharmaceutical Sciences, School of Applied Sciences, University of Huddersfield, Huddersfield, UK.

\section{REFERENCES}

1 Global Initiative for Asthma (GINA), National Heart Lung and Blood Institute, National Institutes of Health. GINA report. Global strategy for asthma management and prevention. Bethesda, National Institutes of Health, 2006.

2 Global Initiative for Obstructive Lung Disease (GOLD), National Heart Lung and Blood Institute, National Institutes of Health. GOLD report. Global strategy for diagnosis, management and prevention of COPD. Bethesda, National Institutes of Health, 2009.

3 BTS/SIGN. British guidelines on the management of asthma. London and Edinburgh, British Thoracic Society and Scottish Intercollegiate Guidelines Network, 2008.

4 Flume PA, O'Sullivan BP, Robinson KA, et al. Cystic fibrosis pulmonary guidelines: chronic medications for maintenance of lung health. Am J Respir Crit Care Med 2007; 176: 957-969.

5 Heijerman H, Westerman E, Conway S, et al. Inhaled medication and inhalation devices for lung disease in patients with cystic fibrosis: a European consensus. J Cyst Fibros 2009; 8: 295-315.

6 Brocklebank D, Ram F, Wright J, et al. Comparison of the effectiveness of inhaler devices in asthma and chronic obstructive airway disease; a systematic review of the literature. Health Technol Assess 2001; 5: 1-149.

7 Dolovich MB, Ahrens RC, Hess DR, et al. Device selection and outcomes of aerosol therapy: evidence-based guidelines: American College of Chest Physicians/American College of Asthma, Allergy, and Immunology. Chest 2005; 127: 335-371.

8 Crompton GK, Barnes PJ, Broeders M, et al. The need to improve inhalation technique in Europe: a report by the Aerosol Drug Management Improvement Team. Respir Med 2006; 100: 1479-1494.

9 Chrystyn H, Price D. Not all asthma inhalers are the same: factors to consider when prescribing a new inhaler. Prim Care Respir J 2009; 18: 243-249.

10 Molimard M, Raherison C, Lignot M, et al. Assessment of handling of inhaler devices in real life: an observational study in 3811 patients in primary care. J Aerosol Med 2003; 16: 249-254.

11 Lavorini F, Magnan A, Dubus JC, et al. Effect of incorrect use of dry powder inhalers on management of patients with asthma and COPD. Respir Med 2008; 102: 593-604.

12 Crompton GK. Problems patients have using pressurized aerosol inhalers. Eur J Respir Dis 1982; 63: 101-104. 
13 Labiris NR, Dolovich MB. Pulmonary drug delivery. Part I: physiological factors affecting therapeutic effectiveness of aerosolized medications. Br J Clin Pharmacol 2003; 5: 588-599.

14 Köbrich R, Rudolf G, Stahlhofen W. A mathematical model of mass deposition in man. Ann Occup Hyg 1994; 38: 15-23.

15 Williamson IJ, Matusiewicz SP, Brown PH, et al. Frequency of voice problems and cough in patients using pressurized aerosol inhaled steroid preparations. Eur Respir J 1995; 8: 590-592.

16 Newman SP, Pavia D, Garland N, et al. Effects of various inhalation modes on the deposition of radioactive pressurized aerosols. Eur J Respir Dis Suppl 1982; 63: 57-65.

17 Usmani OS, Biddiscombe MF, Barnes PJ. Regional lung deposition and bronchodilator response as a function of beta- 2 agonist particle size. Am J Respir Crit Care Med 2005; 172: 1497-1504.

18 Pauwels R, Newman S, Borgstrom L. Airway deposition and the airway effects of antiasthma drugs delivered from metered-dose inhalers. Eur Respir J 1997; 10: 2127-2138.

19 Laube BL. In vivo measurements of aerosol dose and distribution: clinical relevance. J Aerosol Med 1996; 9, Suppl. 1, S77-S91.

20 Laube BL. The expanding role of aerosols in systemic drug delivery, gene therapy and vaccination. Respir Care 2005; 50: 1162-1176.

21 Ilowite JS, Gorvoy JD, Smaldone GC. Quantitative deposition of aerosolized gentamicin in cystic fibrosis. Am Rev Respir Dis 1987; 136: $1445-1449$.

22 Dolovich M, Sanchis J, Rossman C, et al. Aerosol penetrance: a sensitive index of peripheral airways obstruction. J Appl Physiol 1976; 40: 468-471.

23 Dolovich M, Killian D, Wolff R, et al. Pulmonary aerosol deposition in chronic bronchitis: IPPB versus quiet breathing. Am Rev Respir Dis 1977; 115: 397-402.

24 Carstairs HR, Nimmo AJ, Barnes PJ. Autoradiographic visualisation of $\beta$-adrenoceptor subtype in human lung. Am Rev Respir Dis 1985; 132: 541-547.

25 Mak JC, Barnes PJ. Autoradiographic visualization of muscarinic receptor subtypes in human and guinea pig lung. Am Rev Respir Dis 1990; 141: 1559-1568.

26 Adcock IM, Gilbey T, Gelder CM, et al. Glucocorticoid receptor localization in normal and asthmatic lung. Am I Respir Crit Care Med 1996; 154: 771-782.

27 Hogg JC, Chu F, Utokaparch S, et al. The nature of small-airway obstruction in chronic obstructive pulmonary disease. $N$ Engl J Med 2004; 350: 2645-2653.

28 Barnes PJ. Corticosteroids: the drugs to beat. Eur J Pharmacol 2006; 533: 2-14

29 Chua HL, Collis GG, Newbury AM, et al. The influence of age on aerosol deposition in children with cystic fibrosis. Eur Respir J 1994; 7: 2185-2191.

30 Brennan VK, Osman L, Graham H, et al. Device compliance: the need to consider both competence and contrivance. Respir Med 2005; 99: 97-102.

31 Shim C, Williams MH. The adequacy of inhalation of aerosol from canister nebulizers. Am I Med 1980; 69: 891-894.

32 Stoloff SW, Stempel DA, Meyer J, et al. Improved refill persistence with fluticasone propionate and salmeterol in a single inhaler compared with other controller therapies. J Allergy Clin Immunol 2004; 113: 245-251.

33 Charles $\mathrm{T}$, Quinn D, Weatherall $\mathrm{M}$, et al. An audiovisual reminder function improves adherence with inhaled corticosteroid therapy in asthma. J Allergy Clin Immunol 2007; 119: 811-816.

34 Chapman KR, Voshaar TH, Virchow JC. Inhaler choice in primary care. Eur Respir Rev 2005; 14: 117-122.

35 Broeders ME, Sanchis J, Levy ML, et al. The ADMIT series Issues in inhalation therapy. 2) Improving technique and clinical effectiveness. Prim Care Respir J 2009; 18: 76-82.
36 Maugh TH 2nd. FDA phasing out asthma inhalers using CFC propellant. http://latimesblogs.latimes.com/booster_shots/2010/ 04/the-fda-phasing-out-certain-asthma-inhalers.html Date last updated: April 13, 2010. Date last accessed: March, 29, 2011.

37 Gabrio BJ, Stein SW, Velsaquez DJ. A new method to evaluate plume characteristics of hydrofluoroalkane and chlorofluorocarbon metered dose inhalers. Int J Pharm 1999; 186: 3-12.

38 Leach CL, Davidson PJ, Boudreau RJ. Improved airway targeting with the CFC-free HFA-beclomethasone metered-dose inhaler compared with CFC-beclomethasone. Eur Respir I 1998; 12 1346-1353.

39 Leach CL, Davidson PJ, Hasselquist BE, et al. Lung deposition of hydrofluoroalkane 134a beclomethasone is greater than that of chlorofluorocarbon fluticasone and chlorofluorocarbon beclomethasone: a cross over study in healthy volunteers. Chest 2002 122: 510-516.

40 Busse WW, Brazinsky S, Jacobson $\mathrm{K}$, et al. Efficacy response of inhaled beclomethasone dipropionate in asthma is proportional to dose and is improved by formulation with a new propellant. J Allergy Clin Immunol 1999; 104: 1215-1222.

41 Leach CL, Davidson PJ, Hasselquist BE, et al. Influence of particle size and patient dosing technique on lung deposition of HFA-beclomethasone for a metered dose inhaler. I Aerosol Med 2005; 18: 379-385.

42 Bousquet J, Poli G, Acerbi D, et al. Systemic exposure and implications for lung deposition with extrafine hydrofluroalkane beclomethasone dipropionate/formoterol combinations. Clin Pharmacokinet 2009; 48: 347-358.

43 Papi A, Paggiaro P, Nicolini G, et al. Beclomethasone/formoterol vs fluticasone/salmeterol inhaled combination in moderate to severe asthma. Allergy 2007; 62: 1182-1188.

44 Papi A, Paggiaro PL, Nicolini G, et al. Beclomethasone/ formoterol versus budesonide/formoterol combination therapy in asthma. Eur Respir J 2007; 29: 682-689.

45 Newman SP, Weisz AW, Talaee N, et al. Improvement of drug delivery with a breath actuated pressurised aerosol for patients with poor inhaler technique. Thorax 1991; 46: 712-716.

46 Fergusson RJ, Lenney J, McHardy GJ, et al. The use of a new breath-actuated inhaler by patients with severe airflow obstruction. Eur Respir J 1991; 4: 172-174.

47 Barry PW, O'Callaghan C. Inhalational drug delivery from seven different spacer devices. Thorax 1996; 51: 835-840.

48 Richards J, Hirst P, Pitcairn G, et al. Deposition and pharmacokinetics of flunisolide delivered from pressurized inhalers containing non-CFC and CFC propellants. J Aerosol Med 2001; 14: 197-208.

49 Roller CM, Zhang G, Troedson RG, et al. Spacer inhalation technique and deposition of extrafine aerosol in asthmatic children. Eur Respir J 2007; 29: 299-306.

50 Devadason SG, Huang T, Walker S, et al. Distribution of technetium-99m-labelled QVAR delivered using an Autohaler device in children. Eur Respir J 2003; 21: 1007-1011.

51 Lavorini F, Fontana G. Targeting drugs to the airways: the role of spacer devices. Expert Opin Drug Deliv 2009; 6: 91-102.

52 Cohen HA, Cohen Z, Pomeranz AS, et al. Bacterial contamination of spacer devices used by asthmatic children. J Asthma 2005; 42: 169-172.

53 Cole $\mathrm{CH}$. Special problems in aerosol delivery: neonatal and pediatric considerations. Respir Care 2000; 45: 646-651.

54 Wildhaber JH, Waterer GW, Hall GL, et al. Reducing electrostatic charge on spacer devices and bronchodilator response. $\mathrm{Br} \mathrm{J} \mathrm{Clin}$ Pharmacol 2000; 50: 277-280.

55 Pierart F, Wildhaber JH, Vrancken I, et al. Washing plastic spacers in household detergent reduces electrostatic charge and greatly improves delivery. Eur Respir J 1999; 13: 673-678.

56 Janssens HM, Heijnen EMEW, Jong de VM, et al. Aerosol delivery from spacers in wheezy infants aged 0 to 2 years in daily life. Eur Respir J 2000; 16: 850-856. 
57 Barry PW, O'Callaghan C. The effect of delay, multiple actuations and spacer static charge on the in vitro delivery of budesonide from the Nebuhaler. Brit J Clinic Pharm 1995; 40: 76-78.

58 Schulte M, Osseiran K, Betz R, et al. Handling of and preferences for available dry powder inhaler systems by patients with asthma and COPD. J Aerosol Med Pulm Drug Deliv 2008; 21: 321-328.

59 Moore AC, Stone S. Meeting the needs of patients with COPD: patients' preference for the Diskus inhaler compared with the Handihaler. Int J Clin Pract 2004; 58: 444-450.

60 Wilson DS, Gillion MS, Rees PJ. Use of dry powder inhalers in COPD. Int J Clin Pract 2007; 61: 2005-2008.

61 Meakin BJ, Cainey JM, Woodcock PM. Simulated "in use" and "mis-use" aspects of the delivery of terbutaline sulphate from the Bricanyl Turbohaler ${ }^{\mathrm{TM}}$ dry powder inhaler. Int J Pharm 1995; 119: 103-108.

62 Clark AR, Hollingworth AM. The relationship between powder inhaler resistance and peak inspiratory conditions in healthy volunteers - implications for in vitro testing. J Aerosol Med 1993; 6: 99-110.

63 Chrystyn H. Effects of device design on patient compliance: comparing the same drug in different devices. In: Dalby $\mathrm{RN}$, Byron PR, Peart J, et al. Respiratory Drug Delivery Europe 2009. River Grove, Davis Healthcare International Publishing, 2009; pp. 105-116.

64 Chrystyn H, Price D. What you need to know about inhalers and how to use them. Prescriber 2009; 20: 47-52.

65 Everard ML, Devadason SG, Le Souëf PN. Flow early in the inspiratory manoeuvre affects the aerosol particle size distribution from a Turbuhaler. Respir Med 1997; 91: 624-628.

66 Kamin WES, Genz T, Roeder S, et al. Mass output and particle size distribution of glucocorticosteroids emitted from different inhalation devices depending on various inspiratory parameters. J Aerosol Med 2002; 15: 65-73.

67 Pedersen S, Hansen OR, Fuglsang G. Influence of inspiratory flow rate upon the effect of a Turbuhaler. Arch Dis Child 1990; 65: 308-319.

68 Fenton C, Keating GM, Plosker GL. Novolizer: a multidose dry powder inhaler. Drugs 2003; 63: 2437-2445.

69 Koskela T, Malmström K, Sairanen U, et al. Efficacy of salbutamol via Easyhaler unaffected by low inspiratory flow. Respir Med 2000; 94: 1229-1233.

70 Newhouse MT, Nantel NP, Chambers CB, et al. Clickhaler (a novel dry powder inhaler) provides similar bronchodilation to pressurized metered-dose inhaler, even at low flow rates. Chest 1995; 115: 952-956.

71 Nielsen KG, Auk IL, Bojsen K, et al. Clinical effect of Diskus drypowder inhaler at low and high inspiratory flow rates in asthmatic children. Eur Respir J 1998; 11: 350-354.

72 Chodosh S, Flanders JS, Kesten S, et al. Effective delivery of particles with the Handihaler dry powder inhalation system over a range of chronic obstructive pulmonary disease severity. J Aerosol Med 2001; 14: 309-315.

73 Nielsen KG, Skov M, Klug B, et al. Flow dependent effect of formoterol dry-powder inhaled from Aerolizer. Eur Respir J 1997; 10: 2105-2109.

74 Bentur L, Mansour Y, Hamzani Y, et al. Measurement of inspiratory flow in children. Ped Pulmonol 2004; 38: 304-307.

75 Jarvis S, Ind PW, Shiner RJ. Inhaled therapy in elderly COPD patients; time for re-evaluation? Age and Ageing 2007; 36: 213-218.

76 Pedersen S. How to use a rotahaler. Arch Dis Child 1986; 61: 11-14.

77 Boe L, Dennis JH, O'Driscoll BR, et al. European Respiratory Society Task Force on the use of nebulizers. Eur Respir J 2001; 18: 228-242.

78 Smith EC, Denyer J, Kendrick AH. Comparison of 23 nebulizer/ compressor combinations for domiciliary use. Eur Respir J 1995; 8: 1214-1221.
79 Kendrick AH, Smith EC, Wilson RSE. Selecting and using nebulizer equipment. Thorax 1997; 52: S92-S101.

80 Brand P, Beckmann H, Maas Enriquez M, et al. Peripheral deposition of $\alpha_{1}$-protease inhibitor using commercial inhalation devices. Eur Respir J 2003; 22: 263-267.

81 Niven RW, Ip AY, Mittleman S, et al. Some factors associated with the ultrasonic nebulization of proteins. Pharm Res 1995; 12: 53-59.

82 Munster AM, Benstrup E, Jensen JI, et al. Jet and ultrasonic nebulization of chain urokinase plasminogen activator (scu-PA). J Aerosol Med 2000; 13: 325-333.

83 Denyer J, Nikander K, Smith NJ. Adaptive aerosol delivery (AAD) technology. Expert Opin Drug Deliv 2004; 1: 165-176.

84 Wagner A, Vorauer-Uhl K, Katinger H. Nebulization of liposomal $\mathrm{rh}-\mathrm{Cu} / \mathrm{Zn}-\mathrm{SOD}$ with a novel vibrating membrane nebulizer. J Liposome Res 2006; 16: 113-125.

85 Elhissi AM, Karnam KK, Danesh-Azari MR, et al. Formulations generated from ethanol-based proliposomes for delivery via medical nebulizers. J Pharm Pharmacol 2006; 58: 887-894.

86 Kleemann E, Schemhl T, Geesler T, et al. Iloprost-containing liposomes for aerosol application in pulmonary arterial hypertension: formulation aspects and stability. Pharm Res 2007; 24: 277-287.

87 Johnson J, Waldrep JC, Guo J, et al. Aerosol delivery of recombinant human DNAse I: in vitro comparison of a vibrating mesh nebulizer with a jet nebulizer. Respir Care 2008; 53: 1703-1708.

88 Smaldone GC, Berg E, Nikander K. Variation in pediatric aerosol delivery: importance of facemask. J Aerosol Med 2005; 18: 354-363.

89 Sangwan S, Gurses BK, Smaldone GC. Face masks and facial deposition of aerosols. Pediatr Pulmonol 2004; 37: 447-452.

90 Erzinger S, Schueepp KG, Brooks-Wildhaber J, et al. Face masks and aerosol delivery in vivo. J Aerosol Med 2007; 20: Suppl. 1, S78-S84.

91 Smaldone GC, Sangwan S, Shah A. Face mask design, facial deposition, and delivered dose of nebulized aerosols. J Aerosol Med 2007; 20, Suppl. 1, S66-S77.

92 National Asthma Education and Prevention Program, National Institutes of Health: Expert Panel Report 3: Guidelines for the diagnosis and management of asthma. Bethesda, National Institutes of Health, 2007.

93 Zierenberg B, Eicher J, Dunne S, et al. Boehringer Ingelheim nebulizer $\mathrm{BINEB}_{\mathbb{B}}$ a new approach to inhalation therapy. In: Dalby R, Byron PR, Farr SJ, eds. Respiratory Drug Delivery V. Buffalo Grove, Interpharm Press, 1996; pp. 187-193.

94 Zierenberg B. Optimizing the in vitro performance of Respimat $\mathrm{B}$. J Aerosol Med 1999; 12: S19-S24.

95 Newman SP, Steed KP, Reader SJ. Efficient delivery to the lungs of flunisolide aerosol from a new portable hand-held multidose nebulizer. J Pharm Sci 1996; 85: 960-964.

96 Newman SP, Brown J, Steed KP. Lung deposition of fenoterol and flunisolide delivered using a novel device for inhaled medicines. Comparison of Respimate Soft Mist ${ }^{\mathrm{TM}}$ Inhaler with conventional pMDIs with and without spacer devices. Chest 1998; 113: 957-963.

97 Steed KP, Towse LJ, Freund B, et al. Lung and oropharyngeal depositions of fenoterol hydrobromide delivered from the prototype III hand-held multidose Respimat nebuliser. Eur J Pharm Sci 1997; 5: 55-61.

98 Bateman ED, Boushey HA, Bousquet J, et al. GOAL Investigators Group. Can guideline-defined asthma control be achieved? The Gaining Optimal Asthma Control Study. Am J Respir Crit Care Med 2004; 170: 836-844.

99 Donaldson SH, Bennett WD, Zeman KL, et al. Mucus clearance and lung function in cystic fibrosis with hypertonic saline. N Engl J Med 2006; 354: 241-250.

100 Kesser KC, Geller DE. New aerosol delivery devices for cystic fibrosis. Respir Care 2009; 54: 754-767. 
101 Lipworth BJ. Treatment of acute asthma. Lancet 1997; 350: 18-23.

102 Corbridge TC, Hall JB. The assessment and management of adults with status asthmaticus. Am J Respir Crit Care Med 1995; 151: 1296-1316.

103 Salmeron S, Taravella O, Bard M, et al. Modes d'administration des $\beta$-agonistes dans l'asthme. [Modes of administration of $\beta$ agonists in asthma.]. Rev Pneumol Clin 1996; 52: 119-127.

104 Hendeles L, Hatton RC, Coors TJ, et al. Automatic replacement of albuterol nebulizer therapy by metered-dose inhaler and valved holding chamber. Am J Health Syst Pharm 2005; 62: 1053-1061.

105 Jasper AC, Mohsenifar Z, Kahan S, et al. Cost benefit comparison of aerosol bronchodilator delivery methods in hospitalized patients. Chest 1987; 91: 614-618.

106 Turner JR, Corkery KJ, Eckman DE, et al. Equivalence of continuous flow nebuliser and metered dose inhaler with reservoir bag for treatment of acute airflow obstruction. Chest 1988; 93: 476-481.

107 Mestitz H, Copland JM, McDonald CF. Comparison of outpatient nebulized vs. metered dose inhaler terbutaline in chronic airflow obstruction. Chest 1989; 96: 1237-1240.

108 Shortfall SP, Blum J, Oldenburg FA, et al. Treatment of patients hospitalized for exacerbations of chronic obstructive pulmonary disease: comparison of an oral/metered-dose inhaler regimen and an intravenous/nebulizer regimen. Respir Care 2002; 47: $154-158$.

109 Robinson TD, Freiberg DB, Regnis JA, et al. The role of hypoventilation and ventilation-perfusion redistribution in oxygen-induced hypercapnia during acute exacerbations of chronic obstructive pulmonary disease. Am J Respir Crit Care Med 2000; 161: 1524-1529.

110 Durrington HJ, Flubacher M, Ramsay CF, et al. Initial oxygen management in patients with an exacerbation of chronic obstructive pulmonary disease. QJM 2005; 98: 499-504.

111 Zhang L, Mendoza-Sassi RA, Wainwright C, et al. Nebulized hypertonic saline solution for acute bronchiolitis in infants. Cochrane Database Syst Rev 2008; 4: CD006458.

112 Lenney W, Boner AL, Bont L, et al. Medicines used in respiratory diseases only seen in children. Eur Respir J 2009; 34 531-551.

113 European Medicines Agency. Guideline on the requirements for clinical documentation for orally inhaled products (OIP) including the requirements for demonstration of therapeutic equivalence between two inhaled products for use in the treatment of asthma and chronic obstructive pulmonary disease (COPD). www.ema.europa.eu/pdfs/human/ewp/4850108en.pdf Date last updated: March 19, 2008. Date last accessed: March 24, 2011.

114 Cates CJ, Crilly JA, Rowe BH. Holding chambers (spacers) versus nebulisers for beta-agonist treatment of acute asthma. Cochrane Database Syst Rev 2006; 2: CD000052.

115 Dhand R. Inhalation therapy with metered-dose inhalers and dry powder inhalers in mechanically ventilated patients. Respir Care 2005; 50: 1331-1345.

116 Dhand R, Duarte AG, Jubran A, et al. Dose-response to bronchodilator delivered by metered-dose inhaler in ventilatorsupported patients. Am J Respir Crit Care Med 1996; 154: 388-393.

117 Fink JB, Dhand R, Duarte AG, et al. Aerosol delivery from a metered-dose inhaler during mechanical ventilation. An in vitro model. Am J Respir Crit Care Med 1996; 154: 382-387.
118 Mouloudi E, Katsanoulas K, Anastasaki M, et al. Bronchodilator delivery by metered dose inhaler in mechanically ventilated COPD patients: influence of tidal volume. Intensive Care Med 1999; 25: 1215-1221.

119 Waldrep JC, Keyhani K, Black M, et al. Operating characteristics of 18 different continuous-flow jet nebulizers with beclomethasone dipropionate liposome aerosol. Chest 1994; 105: 106-110.

120 Hess DR, Dillman C, Kacmarek RM. In-vitro evaluation of aerosol bronchodilator delivery during mechanical ventilation: pressure-control versus volume control ventilation. Intensive Care Med 2003; 29: 1145-1150.

121 Vecellio L, Guerin C, Grimbert D, et al. In vitro study and semiempirical model for aerosol delivery control during mechanical ventilation. Intensive Care Med 2005; 31: 871-876.

122 O'Riordan TG, Greco MJ, Perry RJ, et al. Nebulizer function during mechanical ventilation. Am Rev Respir Dis 1992; 145: 1117-1122.

123 Miller DD, Amin MM, Palmer LB, et al. Aerosol delivery and modern mechanical ventilation: in vitro/in vivo evaluation. Am J Respir Crit Care Med 2003; 168: 1205-1209.

124 Goode ML, Fink JB, Dhand R, et al. Improvement in aerosol delivery with helium-oxygen mixture during mechanical ventilation. Am J Respir Crit Care Med 2001; 163: 109-114.

125 Duarte AG, Momii K, Bidani A. Bronchodilator therapy with metered-dose inhaler and spacer versus nebulizer in mechanically-ventilated patients: comparison of magnitude and duration of response. Respir Care 2000; 45: 817-823.

126 Manthous CA, Hall JB, Schmidt GA, et al. Metered-dose inhaler versus nebulized albuterol in mechanically-ventilated patients. Am Rev Respir Dis 1993; 148: 1567-1570.

127 Bernasconi M, Brandolese R, Poggi R, et al. Dose-response effects and time course of effects of inhaled fenoterol on respiratory mechanics and arterial oxygen tension in mechanically ventilated patients with chronic airflow obstruction. Intensive Care Med 1990; 16: 108-114.

128 Putensen C, Hormann C, Kleinsasser A, et al. Cardiopulmonary effects of aerosolized prostaglandin E1 and nitric oxide inhalation in patients with acute respiratory distress syndrome. Am J Respir Crit Care Med 1998; 157: 1743-1747.

129 Walmrath D, Schneider T, Schermuly R, et al. Direct comparison of inhaled nitric oxide and aerosolized prostacyclin in acute respiratory distress syndrome. Am J Respir Crit Care Med 1996; 153: 991-996.

130 Hess DR. The mask for noninvasive ventilation: principles of design and effects on aerosol delivery. J Aerosol Med 2007; 20: Suppl. 1, S85-S99.

131 Branconnier MP, Hess DR. Albuterol delivery during noninvasive ventilation. Respir Care 2005; 50: 1649-1653.

132 Calvert LD, Jackson JM, White JA, et al. Enhanced delivery of nebulised salbutamol during non-invasive ventilation. J Pharm Pharmacol 2006; 58: 1553-1557.

133 Haughney J, Price D, Barnes NC, et al. Choosing inhaler devices for people with asthma: current knowledge and outstanding research needs. Respir Med 2010; 104: 1237-1245.

134 Thomas M, Price D, Chrystyn $\mathrm{H}$, et al. Inhaled corticosteroids for asthma: impact of practice level device switching on asthma control. BMC Pulm Med 2009; 9: 1 